\title{
Algunas consideraciones sobre el tratado OMPI relativo a la protección de los organismos de radiodifusión
}

\author{
Some considerations regarding the WIPO broadcasting \\ protection treaty
}

CARLO BENUSSI DÍAZ

Abogado independiente, Chile

RESUMEN El presente trabajo tiene por objeto analizar críticamente las principales propuestas e iniciativas regulatorias planteadas en el debate internacional sobre un nuevo tratado de protección a los organismos de radiodifusión y que, a la fecha, se sustentan especialmente en el último documento publicado por la Organización Mundial de Propiedad Intelectual denominado «Documento de trabajo relativo a un tratado sobre la protección de los organismos de radiodifusión» (SCCR/27/2 REV). Para ello comenzamos deteniéndonos brevemente en el estado del debate internacional para luego centrarnos en la estructura y contenido del documento. Terminamos con algunas consideraciones en cuanto a las principales críticas que se han hecho de él y sus planteamientos.

PALABRAS CLAVE Tratado de protección de los organismos de radiodifusión, organismo de radiodifusión, derechos conexos, propiedad intelectual.

ABSTRACT The article at hand aims to analyse from a critical point of view the main proposals and regulatory initiatives displayed in the inter- 
national debate on a new treaty to protect broadcasters, which to date, is especially supported on the latest document developed for the World Intellectual Property Organization called «Working Document for a Treaty on the Protection of Broadcasting Organizations» (SCCR/27/2 REV). For that, we start briefly with a state of the international debate. Subsequently we will focus on the structure and content of the document, concluding with some considerations regarding the significant reviews of the treaty.

KEYWORDS WIPO broadcasting protection treaty, broadcasting organization, related rights, intellectual property.

\section{INTRODUCCIÓN}

Desde hace algunos años, diversos países y empresas transnacionales han señalado que la protección dada por la regulación internacional de propiedad intelectual a los organismos de radiodifusión es insatisfactoria, sobre todo teniendo en cuenta el desarrollo de las nuevas tecnologías que facilitan los medios para infringir sus derechos. Bajo dicho panorama se viene discutiendo ante la Organización Mundial de Propiedad Intelectual (OMPI) un tratado de protección para tales entidades que actualice y mejore la regulación vigente, persistiendo hasta la actualidad dispares opiniones que alcanzan los más variados tópicos y que - junto a otras razones - no han permitido todavía la adopción de una nueva normativa. ${ }^{\mathrm{I}}$

En este escenario, el presente artículo busca analizar las propuestas regulatorias más importantes y que son la base del tratado en discusión, las cuales hoy están dispuestas en el último documento de trabajo preparado por el Comité Permanente de Derechos de Autor y Derechos Cone$\operatorname{xos}^{2}$ (SCCR por su nombre en inglés) de la OMPI relativo al tratado de protección de los organismos de radiodifusión (SCCR/27/2 REV). Para

I. OMPI, «Documento de trabajo relativo a un tratado sobre la protección de los organismos de radiodifusión» (SCCR/27/2 REV), preparado por la Secretaría del Comité Permanente de Derechos de Autor y Derechos Conexos, del 25 de marzo de 20I4, disponible para descarga directa en formato Word en $<$ http://bit.ly/IfjarKJ>.

2. Véase OMPI, Comité Permanente de Derecho de Autor y Derechos Conexos (SCCR), disponible en <http://bit.ly/IJulBEk>. 
ello revisaremos primero los antecedentes relevantes del tratado junto al estado del debate en el contexto internacional, para luego detenernos en la estructura y contenido del último documento de trabajo, terminando con algunas consideraciones sobre los principales argumentos esgrimidos por aquellos que están en contra del proyecto y las normas que contiene.

\section{ANTECEDENTES DEL TRATADO DE PROTECCIÓN A LOS ORGANISMOS DE RADIODIFUSIÓN}

La globalización, el acceso a la información y el desarrollo continuo de nuevas tecnologías son fenómenos modernos que hoy en día ya no son un misterio para nadie; de hecho, el último reporte de la Universidad de Pennsylvania sobre think tanks del año 20I4, "20I4 Global Go To Think Tank Index Report», concluyó que entre las tendencias mundiales más relevantes de tal año se encuentran la globalización, la era de la información y el cambio tecnológico (McGann, 20I4: I3-8).

Con ello, el esfuerzo innovativo vinculado al desarrollo de dichas nuevas tecnologías se encuentra protegido por la regulación de propiedad intelectual a nivel internacional, constituyendo dicha propiedad un factor clave en el desarrollo económico de los países. Por su parte, grandes empresas tanto nacionales como transnacionales protegen las inversiones que hacen en innovación a través de la normativa de propiedad intelectual, incluyendo las más diversas industrias, como las vinculadas a la tecnología, a la farmacéutica, al contenido audiovisual o a los medios de comunicación masiva (Grunewaldt, 2013: 96).

En Chile, la industria audiovisual generadora de obras protegidas no necesariamente va a confundirse con un organismo de radiodifusión, y ello dependerá si este organismo es el mismo ente creativo titular de los respectivos derechos de propiedad intelectual. Como sabemos, la propiedad intelectual se desglosa doctrinariamente en propiedad industrial y derechos de autor. ${ }^{3}$ Junto a estos últimos se encuentran los derechos

3. Los derechos de autor comprenden un conjunto de facultades o derechos concedidos a los creadores por sus obras literarias o artísticas, incluyendo: obras literarias, programas informáticos, bases de datos, películas, composiciones musicales, coreografías, pinturas, fotografías, obras arquitectónicas, mapas, etc. Véanse los artículos I y 3 de la Ley I 7.336 . 
conexos, que corresponden a aquellos que tienen como objeto de protección ciertas manifestaciones que se vinculan con la difusión de obras del ingenio y que en nuestro ordenamiento jurídico se encuentran tratados en el título II de la Ley I 7.336 de Propiedad Intelectual (LPI) bajo la denominación «Derechos conexos al derecho de autor». Esto es así porque estos derechos no buscan proteger la creación realizada, sino que una forma particular de difundirla o masificarla ${ }^{4}$ (Antequera, I998: 56).

En nuestro país y a nivel internacional los titulares de los derechos conexos son tres, los artistas intérpretes o ejecutantes con relación a sus interpretaciones o ejecuciones, los productores de fonogramas con relación a sus fonogramas y los organismos de radiodifusión con relación a sus radiodifusiones. ${ }^{5}$ El artículo 5 de la LPI define en su letra l) a los organismos de radiodifusión como «la empresa de radio o de televisión que transmite programas al público» y, por su parte, en su letra n) define emisión o transmisión como «la difusión por medio de ondas radioeléctricas, de sonido o de sonidos sincronizados con imágenes». Combinando ambas definiciones podemos concluir que el organismo de radiodifusión, según las normas de derecho interno, es aquella empresa de radio o de televisión que difunde por medio de ondas radioeléctricas programas al público y que el objeto de protección de los derechos conexos en este caso corresponde a la señal radiodifundida (Cooper, 20I I: I 5-I6).

4. El artículo 69 de la LPI reza de la siguiente forma: «Los organismos de radiodifusión o de televisión gozarán del derecho de autorizar o prohibir la fijación de sus emisiones y la reproducción de las mismas. La retransmisión de las emisiones de dichos organismos o su comunicación al público en locales a los que éste tenga libre acceso, otorgará a la empresa derecho a una retribución, cuyo monto fijará el Reglamento. En el caso de los permisionarios de servicios limitados de televisión, éstos no podrán emitir ni retransmitir, por cualquier medio, en su oferta programática, señales pertenecientes a los concesionarios de radiodifusión televisiva de libre recepción, sin la expresa autorización de éstos. La emisión y retransmisión de tales señales dará al concesionario el derecho a una retribución, que deberá ser acordada previamente por las partes. Los organismos de radiodifusión o televisión podrán realizar fijaciones efímeras de interpretaciones o ejecuciones de un artista con el único fin de utilizarlas en emisión, por el número de veces acordado, quedando obligados a destruirlas inmediatamente después de la última transmisión autorizada».

5. En un sentido amplio se ha señalado que la expresión derechos conexos también incluiría a los editores acerca de la disposición tipográfica de sus ediciones publicadas y los de los creadores de bases de datos (Ficsor, 2003: 286). 
El mismo sentido que sostiene nuestra LPI acerca de los organismos de radiodifusión es compartido por la Convención de Roma de I96I y el Acuerdo sobre los Aspectos de los Derechos de Propiedad Intelectual relacionados con el Comercio (ADPIC) ${ }^{6}$ de 1995. Si bien la Convención de Roma no contiene una definición de organismos de radiodifusión, en su artículo 3 letra f) define a la emisión como aquella que se efectúa inalámbricamente $\mathrm{y}$, por lo tanto, se ha entendido globalmente desde su creación al organismo radiodifusor como aquel que sólo transmite su señal a través del aire. Esto es lo que se conoce como organismos de radiodifusión en su sentido tradicional (SCCR, 2002: 2-3).

La definición de organismo de radiodifusión provista por nuestro derecho interno no es suficiente para comprender cabalmente cuáles entidades se entienden contempladas cuando en las negociaciones en la OMPI las delegaciones de los Estados se refieren al mejoramiento de los derechos de los organismos de radiodifusión. En el contexto del tratado y sus debates, se ha entendido a estos organismos como aquellos que transmiten su señal tanto por el aire o inalámbricamente, como aquellos que lo hacen por medio de cable o hilo. ${ }^{7}$ Todo esto en razón de que, en ciertos mercados como el estadounidense, la televisión por cable juega un papel de igual o mayor importancia en la sociedad que la televisión que transmite inalámbricamente y, por lo tanto, en esos casos sería inoficioso dejarlos fuera de una nueva regulación (Muñoz, 2007: 3-4).

Cabe destacar que los organismos de radiodifusión, como empresas de televisión y radio, son protegidos globalmente por derechos de propiedad intelectual al igual que en Chile. La importancia de dichas entidades en los países es enorme, sobre todo como difusores de conocimiento, cultura e ideas. Es por ello menester tener presente que la regulación que se adopte respecto de los radiodifusores debe ser la apropiada por el impacto a nivel social que pueda tener, debiendo buscarse un óptimo entre los incentivos de la innovación y avance junto con el de la sociedad de alcanzar la difusión del conocimiento (Sehgal y Mathur, 201 I: 402).

Como dijimos, la protección de los derechos de estos organismos

6. Anexo del Tratado de la Organización Mundial de Comercio. El 4 de noviembre del año 2003 se publicó en el Diario Oficial la Ley r9.9I 2 que adecuó la legislación nacional a los acuerdos de la Organización Mundial de Comercio.

7. Que en Chile se conocen como operadores de televisión por cable. 
radiodifusores no sólo se reduce a la normativa interna de los países, sino que también a la existente en el ámbito internacional. Nuestro país, como parte del mundo globalizado, es Estado miembro de la OMPI ${ }^{8}$ desde el año I975 y ha suscrito más de diez tratados impulsados por dicha organización. La OMPI busca desarrollar y proteger la propiedad intelectual en todo el mundo, y ha sido la entidad donde los Estados partes a través de sus delegaciones han propulsado la creación del tratado de protección a los organismos de radiodifusión por medio del Comité Permanente de Derechos de Autor y Derechos Conexos. ${ }^{9}$ Acerca de los derechos conexos de los organismos de radiodifusión, la OMPI en sus estudios ha determinado que varios países alrededor del mundo no conceden dichos derechos respecto de sus señales pero que, por otro lado, consideran que aquéllas corresponden a una categoría de obra protegida en virtud del derecho de autor. De esta forma se ha establecido que gran parte de las legislaciones tienen normas que protegen a los organismos de radiodifusión, existiendo, eso sí, diferencias en la forma en que conceden la protección (SCCR, I998: 9).

En la esfera internacional, el contexto en el cual nos situamos de protección a los organismos de radiodifusión tiene como pilares primordiales la Convención de Roma y el Acuerdo sobre los ADPIC, ambos ratificados por Chile. La Convención de Roma fue el primer instrumento internacional en regular directamente a los organismos de radiodifusión, otorgando derechos mínimos de protección sobre su transmisión. La doctrina ha entendido que la intención de este tratado fue subordinar los derechos conexos a los derechos de autor, y no al revés, lo cual se

8. La OMPI es el organismo de las Naciones Unidas creado en I967 destinado a servir de foro global en lo que atañe a servicios, políticas, cooperación e información en materia de propiedad intelectual. Cuenta con I 88 Estados miembros. Para mayor referencia dirigirse a $<$ http://www.wipo.int $>$.

9. Dicho comité fue creado durante el bienio I998-I999 para examinar cuestiones de derecho sustantivo o de armonización respecto de los derechos de autor y los derechos conexos. Está compuesto por todos los Estados miembros de la OMPI y formula recomendaciones que luego son conocidas por la Asamblea General o en una conferencia diplomática. A la fecha, el comité, además de estar trabajando en la actualización de la normativa para los organismos radiodifusores, también se encuentra examinando el tema de las limitaciones y excepciones al derecho de autor. Véase OMPI, Limitaciones y excepciones, en <http://bit.ly/ISzkjN3 $>$. 
manifiesta en la duración de la protección de veinte años desde que se efectuó la transmisión por la entidad radiodifusora. En cuanto al Acuerdo sobre los ADPIC, éste mantuvo la regulación de la Convención de Roma, confiriendo los mismos derechos mínimos y una duración de la protección de veinte años contados desde el final del año en que se haya realizado la transmisión (Sehgal y Mathur, 20I I: 405).

Los promotores del tratado estiman que los dos instrumentos anteriores confieren una protección limitada debido a que, en la época que se crearon, bastantes avances técnicos aún estaban en pañales. En este sentido, la creación de un nuevo instrumento internacional para cubrir la tercera categoría tradicional de beneficiarios de derechos conexos, a saber, los organismos de radiodifusión, se estimó pertinente desde el año I 998 con el fin de actualizar las normas vigentes al respecto (Sehgal y Mathur, 20II: 403).

\section{JUSTIFICACIÓN DEL TRATADO}

A partir de sus investigaciones (cf. Screen Digest, 20I0a), la OMPI ha sostenido que uno de los mayores problemas que el avance de las nuevas tecnologías de la información ha supuesto para los organismos de radiodifusión alrededor del mundo ha sido la utilización no autorizada de sus señales. Así, se han detectado fundamentalmente cuatro tipos de usos no autorizados especialmente perniciosos para la actividad de estas entidades, a saber: a) la piratería informática física; b) el acceso no autorizado mediante el uso de dispositivos físicos; c) el acceso extraterritorial a la televisión; y d) la retransmisión (o redifusión) no autorizada de señales, que abarca la redistribución de las señales emitidas con o sin el consentimiento expreso del titular de los derechos. A su vez, los estudios de la OMPI han distinguido entre: a) piratería material, que incluye grabaciones no autorizadas de emisiones en cintas de video, DVD o USB; y b) piratería virtual con, por ejemplo, la redistribución no autorizada a través de la red de internet, especialmente de encuentros deportivos transmitidos en vivo (Screen Digest, 20Ioa: 5-6).

Otros informes patrocinados por los organismos de radiodifusión y que confirman la piratería de señales han establecido que en el año 2004 el uso no autorizado se incrementó un ciento cincuenta por ciento en comparación al año anterior; que el siete por ciento de dicha piratería se 
produce en Estados Unidos; y que la propagación de internet como medio de distribución de información de naturaleza global ha generado que el impacto de dicha piratería sobre sus ingresos sea mucho más fuerte ${ }^{\text {1o }}$ (Balganesh, 2007: I324).

Cabe mencionar que un importante adherente a la creación del tratado ha sido la industria vinculada a la transmisión por televisión de eventos deportivos, la cual en la mayoría de los países no goza de derechos de propiedad intelectual respecto del contenido al no ser creación del intelecto humano. Dicha industria deportiva constituye hoy un sector de gigantescas ganancias a nivel mundial, y que ha visto cómo el uso no autorizado de sus señales merma sus utilidades. En este sentido, ha señalado que el costo de la piratería de sus señales que transmiten eventos deportivos ascendió a I.942 millones de dólares en el año 2009. Para este sector de la economía es clave que en la protección del nuevo tratado se tome en cuenta la importante inversión que se hace para transmitir los eventos deportivos, que se regule la piratería a través de la red de internet y que se regule sobre las medidas tecnológicas de protección (véase Croella, 20I I).

Ante el uso no autorizado de señales (o piratería de señales), la industria no sólo ha expresado como consecuencia las pérdidas monetarias derivadas de aquello, sino que también ha aducido una variación de la inversión en los mercados, la cual se encontraría condicionada por la existencia de un mayor o menor respeto y observancia a la regulación de propiedad intelectual. Con ello, se ha manifestado que la realidad de una economía que tiene una pobre normativa de propiedad intelectual y cuya piratería es alta se traduce en un menor crecimiento económico, menor creación de empleos y menor innovación. Cabe destacar que estos argumentos no sólo han sido expuestos por la industria de los organismos radiodifusores, sino que han sido la lógica con la que la mayoría de la industria de medios (música, software, películas y libros) ha operado desde los años ochenta y ha fomentado la lucha contra la piratería (Karaganis, 20I2: IO).

Si bien el objeto de protección de la nueva regulación de derechos conexos de los organismos de radiodifusión es la señal radiodifundida,

ıo. Para ver la declaración conjunta de las uniones de organismos de radiodifusión hecha en el año 2014 respecto del uso no autorizado de señales, véase el documento en pdf en <http://bit.ly/rOufHY6>. 
no es posible desconocer que a través de dicha señal ${ }^{\mathrm{II}}$ está incorporado contenido susceptible de estar protegido por derechos de autor. Como sabemos, las empresas de televisión envían imágenes y/o sonidos a través de ondas hertzianas para su recepción por el público y, en definitiva, lo que el público busca recibir no es la señal misma, sino el contenido que dicha señal lleva. Esto nos permite afirmar que los diversos mecanismos de uso no autorizado de las señales se encuentran íntimamente ligados con el contenido que transportan por la naturaleza misma de ellas, pero sin olvidar que ambos son elementos independientes tanto en cuanto objetos de derechos y titularidad. Dada esta realidad de inseparable conexión entre la señal y su contenido, no podemos nada menos que suponer el eventual conflicto que el otorgamiento de nuevos derechos a los radiodifusores podría generar con los derechos ya existentes sobre el contenido y que, como veremos, ha sido ya advertido por los Estados en el documento de trabajo elaborado (Bates y Wells, 2007: 4-5).

Lo anterior está íntimamente relacionado con lo que muchas organizaciones no gubernamentales han aportado en el debate, sobre todo en cuanto a que el otorgamiento de mayor protección a los organismos de radiodifusión podría generar un impacto en el contenido incluido en la señal y que puede estar sujeto a derechos de autor o encontrarse en el dominio público. De esta forma, indican que se pasaría a crear una nueva capa de protección que entorpecería el actual panorama de los derechos de autor, perjudicando tanto a los titulares de derechos como a los usuarios de la sociedad civil en la utilización de obras del dominio público que hayan sido transmitidas por medio de la señal de un organismo de radiodifusión. ${ }^{\mathrm{I2}}$ Dentro de estas entidades que se han manifestado contrarias al tratado se encuentran: Electronic Frontier Foundation, IP Justice, Public Knowledge, Union for the Public Domain, Consumer Project on Technology y Computer Professionals for Social Responsibility, entre muchas otras ${ }^{13}$ (Akester, 2006: 45).

I I. Según la OMPI, la señal de los organismos de radiodifusión corresponde a toda energía detectable que pueda transportar información (Comité Permanente de Derechos de Autor y Derechos Conexos, I998: 5-II).

I2. Creative Commons, WIPO's Broadcasting Treaty: Still Harmful, Still Unnecessary, I4 de noviembre de 20I2, disponible en <http://bit.ly/IgImRI4>.

I3. Dichas posturas se pueden revisar en las siguientes páginas webs: CPSR, CPSR 
Ahora bien, luego de que en la OMPI se adoptaran los tratados sobre Derecho de Autor (WIPO Copyright Treaty, WCT) y sobre Interpretación o Ejecución y Fonogramas ${ }^{\mathrm{I4}}$ (WIPO Performances and Phonograms Treaty, WPPT) que no incluyeron disposiciones para los organismos de radiodifusión, desde el año I998 y en concordancia con la agenda digital de la OMPI, se ha instaurado el debate acerca de la creación de un tratado de propiedad intelectual que confiera una mejor y más actualizada protección a estos organismos. Una protección acorde a los actuales avances tecnológicos, como la tecnología digital, las redes inalámbricas, la televisión vía dispositivos móviles e internet. Es así como desde I998, en todas y cada una de las reuniones —ordinarias y extraordinariasdel comité se ha debatido sobre un nuevo instrumento para los organismos de radiodifusión.

Como ya vimos, los impulsos para la concreción de un tratado vienen, además de los Estados miembros de la OMPI, de diversos organismos radiodifusores y empresas transnacionales que señalan que, con la convergencia de las nuevas tecnologías de la información y comunicaciones, se han ampliado enormemente las formas, oportunidades y posibilidades de utilizar de manera no autorizada las señales y contenidos radiodifundidos. Puntualizan además que hoy en día nuevos derechos son imperiosos para responder al reciente entorno digital que plantea múltiples desafíos — tanto técnicos como financieros- de gran magnitud para los organismos de radiodifusión. Desde el inicio, la influencia de estos organismos radiodifusores en la prosecución del acuerdo en la OMPI fue evidente, siendo la primera propuesta de tratado una creación de un conjunto de estas entidades, quienes tienen gran relevancia y que califican dentro de la OMPI en la categoría de organizaciones no gubernamentales $^{15}$ (Muñoz y Musungu, 2010: I 87).

Opposes WIPO Broadcast Treaty Proposal, disponible en <http://bit.ly/ICTacRv>; Electronic Frontier Foundation, Joint Statement of Certain Civil Society, Rightsholders, Cablecasters and Webcasters, and Private Sector Representatives for the 22nd Session of the SCCR, disponible en formato pdf en <http://bit.ly/ISzlI6u>; y Public Knowledge, The Broadcast Treaty vs. Broadcast Law, disponible en $<$ http://bit.ly/IHOh2EP>.

I4. En estos tratados por primera vez se incluyen normas internacionales relativas a medidas tecnológicas de protección y sistemas de gestión de derechos en el entorno digital.

I 5. Dicha calificación se confiere independiente de su naturaleza con o sin fines de lucro. 
En el año 200I, la adopción del tratado pasó a ser uno de los principales objetivos del comité pero, aun así, desde ese entonces no ha sido posible encontrar un punto en común entre los países que haga factible concluirlo. Además, hay que señalar que en los últimos años en el contexto internacional, y bajo el alero de la OMPI, también se han alcanzado otros acuerdos importantes en materia de derechos de autor y derechos conexos, como los tratados de Marrakech ${ }^{16}$ y de Beijing, ${ }^{17}$ los cuales también han sido un factor de retraso en la discusión sobre los organismos radiodifusores.

En el tratado propuesto de actualización normativa para los radiodifusores confluyen simultáneamente una gran cantidad de intereses que tienen implicancias desde lo político hasta lo económico, pasando inclusive por lo social, representado fundamentalmente por las organizaciones de consumidores y usuarios. Con ello, hay que destacar que desde el año 2004 hubo un cambio importante en la discusión del tratado, tomando partido diversas entidades que antes no se habían hecho parte, incluyendo organizaciones no gubernamentales de consumidores, de intereses públicos y representantes de la industria tecnológica que aportaron mayor debate y contenido (Muñoz y Musungu, 2010: I 89).

A pesar de haber transcurrido más de diez años desde que se promovieron las discusiones relativas a la implementación de este tratado, todavía quedan cabos sueltos sobre varios factores importantes, lo que dispuso, entre otras cosas, que en el año 2006 la Asamblea General de la OMPI rechazara llamar a una conferencia diplomática solicitada por el comité. ${ }^{18}$ Cabe destacar que ese mismo año el comité decidió no persistir en dos temas altamente controvertidos: el webcasting, que corresponde a la transmisión de contenido a través de la red global de internet; y el simulcasting, que es la transmisión simultánea por medio del aire (espectro radioeléctrico) e internet. El objetivo del comité de desplazar

I6. Tratado de Marrakech para facilitar el acceso a las obras publicadas a las personas ciegas, con discapacidad visual o con otras dificultades para acceder al texto impreso. Fue adoptado el 27 de junio del año 2013 en Marrakech.

I7. Tratado de Beijing sobre Interpretaciones y Ejecuciones Audiovisuales. Fue adoptado por la conferencia diplomática sobre la protección de la fijación interpretaciones y ejecuciones audiovisuales, celebrada en Beijing del 20 al 26 de junio del año 20 I 2.

I8. Las conferencias diplomáticas son necesarias en la OMPI para llevar a cabo las negociaciones finales de un tratado y su posterior adopción. 
dichos temas fue poder alcanzar mayores puntos de consenso entre los involucrados para la conclusión más rápida del tratado. Con todo, las controversias se mantuvieron (Lee, 2009: 2).

El año 2007, la Asamblea General de la OMPI acordó que el tratado debería enfocarse a la señal radiodifundida, con la intención de evitar que se otorguen otros derechos a los organismos que pudieran alcanzar la programación o contenido incluido en dicha señal y mejorar la respectiva protección en un sentido tradicional. También en el año 2007 se celebraron dos sesiones especiales del comité dedicadas exclusivamente a debatir sobre el tratado ${ }^{19}$ (Asamblea General OMPI, 2014: I).

En julio del año 20I2, en la reunión SCCR24, el comité reafirmó el mandato de la Asamblea General manifestando su intención de alcanzar un tratado con un enfoque tradicional, o sea, basado exclusivamente en la señal radiodifundida. Ese mismo año el comité recomendó a la Asamblea General convocar a una conferencia diplomática para el año 2014, lo que se aprobó pero no se logró concretar posteriormente. En la actualidad, el comité espera que se convoque una conferencia diplomática para el año 2016 según el trabajo que se logre en el año 20I5, todo esto en atención al documento de trabajo SCCR/27/2 REV ${ }^{20}$ (Woods, 20I4: I6).

En el año 2014 el comité celebró tres reuniones, ${ }^{21}$ teniendo como documento de trabajo el SCCR/27/2 REV que corresponde al más actualizado de su tipo hasta la fecha y que contiene las propuestas normativas que forman la base de la discusión ante el comité. ${ }^{22}$ En dichas sesiones no se lograron alcanzar acuerdos suficientes para efectuar recomendaciones a la Asamblea General de la OMPI. Durante las reuniones, se debatieron

I9. Dichas reuniones especiales fueron las SCCR/S I y SCCR/S2.

20. Para mayores referencias sobre el avance del debate a lo largo de los años dirigirse a Knowledge Ecology International, Timeline of WIPO negotiations on a Treaty for the Protection of Broadcasting Organizations, disponible en <http://bit.ly/IDs 5p4m>. Para revisar los detalles de la $25 .^{\circ}$ sesión de la Asamblea General de la OMPI, véase <http:// bit.ly/ISzmQHf>.

2I. La reunión SCCR/27 se celebró desde del 28 de abril al 2 de mayo, la SCCR/28 desde el 30 de junio al 4 de julio y la SCCR/29 del 8 al I 2 de diciembre. Para ver todas los informes de las reuniones del comité dirigirse a OMPI, Standing Committee on Copyright and Related Rights, disponible en $<$ http://bit.ly/ıCNgFxB $>$.

22. Dicho documento está disponible en su versión en español en <http://bit. ly/rTNSPpD>. 
temas atingentes a la categoría de las plataformas, las distintas actividades que debieran incluirse en el objeto del tratado, y al alcance que debería tener la protección que se dará a los organismos de radiodifusión (Asamblea General OMPI, 20I 5: 27).

Las reuniones del comité para el año $20 \mathrm{I}_{5}$ (SCCR 30 y SCCR $3 \mathrm{I}$ ) están fijadas para celebrarse entre el 29 de junio y 3 de julio, y 7 y I I de diciembre. Se pretende seguir trabajando en el tratado como uno de sus principales objetivos (en conjunto con las limitaciones y excepciones a los derechos de autor). De hecho, la agenda de la SCCR 30 ya contempla dentro de sus puntos revisar el tratado para los organismos de radiodifusión.

Como vemos, el avance de este instrumento ha sido bastante lento y complicado principalmente por lo delicado del tema para los diversos miembros, pero la postura de algunos Estados y entidades de radiodifusión es seguir presionando fuerte en la OMPI para su concreción. ${ }^{23}$ Si bien hoy la gran mayoría de los Estados miembros —incluyendo los

23. El Representante de la Unión Europea de Radiodifusión (UER) ha señalado: «después de tantos años de debate, ya se ha dicho todo lo que valía la pena decir en ese contexto. Está claro que se corre el riesgo de que el SCCR pierda credibilidad. En I993, tres años antes de la adopción de los bien conocidos Tratados Internet de la OMPI, la UER publicó un artículo sobre la necesidad de actualizar la Convención de Roma en lo que respecta a los derechos de los organismos de radiodifusión, destacando las lagunas de ese Convenio. Ese tipo de retraso excluye la posibilidad de avanzar y resulta incomprensible para el mundo exterior. El Representante dijo que se pregunta cómo puede explicarse que todos los derechos hayan sido actualizados a escala internacional salvo los derechos de los organismos de radiodifusión. Por supuesto que se trata de un proceso sujeto al acuerdo político entre numerosos Estados miembros de todo el mundo, pero cuando ese mismo proceso se aplicó a los Tratados Internet de la OMPI sólo se necesitaron 18 meses. Aducir que ha cambiado el entorno político equivaldría a ignorar el hecho de que, desde el primer día de las negociaciones, la abrumadora mayoría de los miembros del SCCR reconoció la necesidad de un tratado sobre el tema. Los derechos de los organismos de radiodifusión sólo figuran en una disposición de la Convención de Roma. Estima que entablar un debate sobre una disposición durante veinte años resulta inconcebible. El Representante subrayó asimismo que ese retraso tiene efectos negativos en el mundo exterior, puesto que da la impresión de que no se está tomando en serio la lucha contra la piratería en internet. Observó además que tolerar la piratería tendría un efecto dominó en la lucha contra la misma, dando lugar a una pérdida de respeto por el derecho de autor y a una desvalorización del derecho de autor y derechos conexos. A las empresas representadas por la UER se le están agotando los recursos y la paciencia como para seguir interesándose en el proceso» (Asamblea General OMPI, 20 I 5: 40). 
países en desarrollo- están conscientes de que se debe actualizar la normativa de los radiodifusores, no todos comparten las normas propuestas y sus alcances. De acuerdo al informe extendido por la OMPI en enero del año $2015{ }^{24}$ que contiene las declaraciones de las delegaciones sobre la labor del comité, se puede evidenciar que los Estados que buscan más asiduamente una rápida concreción del tratado son: Japón, ${ }^{25}$ la Unión Europea y el grupo de países africanos. ${ }^{26}$ Por su parte, algunos Estados miembros que han manifestado una postura más neutra sobre el tema han sido: Uruguay, ${ }^{27}$ Perú, Brasil, México y República Checa (Asamblea General OMPI, 20I 5: 27-45).

24. Informe aprobado por la Asamblea General del cuadragésimo sexto periodo de sesiones $\left(25 .^{\circ}\right.$ extraordinario).

25. La delegación de Japón señaló expresamente: «la Delegación hizo suya la declaración formulada por el Grupo B, e instó a centrarse en el establecimiento de un marco internacional para proteger a los organismos de radiodifusión en respuesta a la rápida digitalización del mundo. El objetivo es adoptar un tratado lo antes posible, puesto que ya han transcurrido i 6 años desde que se iniciaron las negociaciones sobre la materia. Señaló que los organismos de radiodifusión de todo el mundo esperan con sumo interés dicho tratado. Añadió que el Gobierno del Japón ha participado activamente en los debates sobre la cuestión y ha presentado varias propuestas» (Asamblea General OMPI, 201 5: 33).

26. Los Estados miembros del grupo africano que presentaron opiniones en dicho sentido fueron: Sri Lanka, Senegal, Costa de Marfil, Argelia, Kenia, Nigeria, Sudáfrica y Egipto. La delegación de Sri Lanka sostuvo: «La Delegación observó que el tratado sobre los organismos de radiodifusión reviste importancia para su país, pues esos organismos desempeñan una función importante para el desarrollo de los países. Así pues, estima que es conveniente acelerar la labor en relación con dicho tratado. La Delegación afirmó asimismo que en las siguientes sesiones del SCCR se debe asignar prioridad a esta cuestión, para que se pueda convocar una conferencia diplomática en 20I6» (Asamblea General OMPI, 201 5: 37).

27. La delegación de Uruguay expuso: «Asimismo, declaró que la labor futura deberá ser equilibrada y representativa de los intereses de todas las partes. Las tres cuestiones que se examinan en el SCCR son de igual importancia. Afirmó que las delegaciones que están tratando de limitar los debates sobre las limitaciones y excepciones, por ejemplo, con la creencia de que así acelerarán la labor sobre otras cuestiones, tales como los organismos de radiodifusión, deben revisar su postura. Señaló que es necesario adoptar un enfoque más amplio. Cuando todas las delegaciones estén decididas y sus intereses se vean reflejados en el futuro programa, se avanzará mucho más rápido respecto de esas cuestiones. Si hay grupos de países que se sienten frustrados, no habrá mucho margen para lograr acuerdos y mantener una actitud positiva en las negociaciones. Por último, reiteró su firme compromiso con los debates» (Asamblea General OMPI, 20I 5: 35-36). 


\section{PUNTOS DE DISCREPANCIA}

Los puntos de discordia existentes actualmente entre los Estados miembros de la OMPI son: a) la definición del objeto de protección; b) el mecanismo de protección; c) los derechos que deberían conferirse a los organismos de radiodifusión y si estos debieran ser nuevos derechos exclusivos; d) el tiempo de la protección; e) las limitaciones y excepciones que deberían aplicarse; f) la real necesidad del tratado para los organismos radiodifusores, entre varios otros (Muñoz y Musungu, 20I0: I 88).

En lo que se refiere al objeto de protección, se ha discutido sobre si la protección debe ser conferida sólo a la señal transmitida a través de aire y cable, o respecto de cualquier plataforma donde el contenido sea emitido, como internet. Este tema ha sido de amplia discusión, y ocasionó - como vimos- que en el año 2006 la Asamblea General dispusiera enfocarse sólo en la señal, lo cual para algunas entidades y Estados miembros (como Estados Unidos) restaría de eficacia al eventual tratado teniendo presente el alcance actual de las nuevas tecnológicas vía redes informáticas. Con todo, aún persisten diferencias sobre cómo un tratado enfocado sólo en la señal del organismo radiodifusor debe ser construido (Sehgal y Mathur, 20I I: 406).

Sobre el mecanismo de protección, se ha debatido sobre si se debe propender a la utilización de herramientas que hagan ilegal el quebrantamiento de medidas tecnológicas de protección, lo cual para sus detractores conllevaría a limitar el uso legal de obras transmitidas por los organismos. ${ }^{28}$ Sobre las limitaciones y excepciones, la mayoría de los Estados sostiene que deben aplicarse en algún grado, sin embargo, la discrepancia se ha generado sobre si éstas deben ser especificadas taxativamente en el tratado o sólo se debe dar una norma general para que los propios países decidan de acuerdo a su propia realidad nacional. Finalmente, acerca del tiempo de protección los debates mayoritariamente se han concentrado en el otorgamiento de cincuenta años o mantener los veinte años que otorga la Convención de Roma y el Acuerdo sobre los ADPIC (Sehgal y Mathur, 20I I: 406).

Por último, es importante tener presente que la postura de los países

28. Véase OMPI, La protección de los organismos de radiodifusión, disponible en $<$ http://bit.ly/ıHOcjTz>. 
acerca del otorgamiento de derechos a los organismos de radiodifusión se puede distinguir si estos han ratificado o no la Convención de Roma. Aquellos que son parte, por lo general señalan que es posible mejorar los derechos exclusivos de las entidades de radiodifusión, o incluso extenderlos a áreas no tradicionales como el webcasting. Por otro lado, aquellos que no son parte de la Convención parecen no tan de acuerdo con el otorgamiento de derechos exclusivos a dichos organismos, por el evento de que puedan perjudicar a la ciudadanía en el acceso a las obras (Lee, 2009: 3).

\section{CONTENIDO ACTUAL DEL TRATADO Y SU ESTRUCTURA}

Del 8 al I 2 de diciembre de 20I4, el Comité celebró su vigésima novena sesión en la cual se trabajó con el documento SCCR/27/2 REV y los documentos técnicos oficiosos sobre conceptos, el objeto de la protección y los derechos que han de concederse a las entidades radiodifusoras. Se invitó también a la Secretaría a actualizar algunos documentos, entre otras cosas. ${ }^{29}$ Como se puede ver del contenido de dicha reunión, el debate en temas de fondo como los conceptos y sus definiciones dan cuenta que, a lo largo de los años de discusión, las posiciones de los Estados miembros no han logrado congeniar en una única voluntad apta para la adopción de un instrumento internacional vinculante. Según la propia agenda preparada por la Secretaría, los debates acerca del tratado continuarán en las próximas sesiones del Comité del año 2015.

$\mathrm{El}$ «Documento de trabajo relativo a un tratado sobre la protección de los organismos de radiodifusión» contiene I 6 artículos cuya denominación no ha sido modificada desde el año 2012 y, a continuación, un anexo. A lo largo del documento se presentan a modo de referencia diversas posiciones específicas de los Estados miembros. El nombre de los artículos se ha dispuesto de la siguiente manera: artículo I, «Relación con otros convenios y tratados»; artículo 2, «Principios generales»; artículo 3, «Protección y promoción de la diversidad cultural»; artículo 4, «Defensa de la competencia»; artículo 5, «Definiciones» (con dos variantes, A y B); artículo 6, "Ámbito de aplicación» (con dos variantes,

\footnotetext{
29. El resumen de la presidencia de dicha reunión se puede revisar en <http://bit. ly/IOujQLR>.
} 
A y B); artículo 7, «Beneficiarios de la protección» (con dos variantes respecto de los párrafos, A y B); artículo 8, «Trato nacional» (con dos variantes, A y B); artículo 9, «Protección de los organismos de radiodifusión» (con dos variantes, A y B); artículo ro, «Limitaciones y excepciones» (con tres variantes, A, B y C); artículo I I, «Plazo de protección (con tres variantes, A, B y C); artículo I 2, sin título definido aún (con cuatro variantes, Ar y A2 sobre protección de la codificación e información; y BI y B2 sobre obligaciones relativas a las medidas tecnológicas); artículo $\mathrm{I}_{3}$, «Obligaciones relativas a la información para la gestión de derechos» (este artículo está relacionado con las variantes B del artículo I 2 y que se debe suprimir si se conservan las variantes A de aquél); artículo I4, "Disposiciones sobre la observancia de los derechos»; artículo I 5, «Formalidades»; y artículo I6, "Aplicación en el tiempo».

El anexo del documento de trabajo lo dividimos — con el sólo propósito de ser más claros- en tres grupos de la siguiente forma:

- Propuestas del Gobierno de la India concernientes a la variante A del artículo $53^{30}$ al artículo 6 referentes a la variantes A y B; al artículo 7 como variante; al artículo 9 como variante y al artículo I 2 como variante.

- Propuesta del Gobierno de Japón relativa a un nuevo artículo 6 bis titulado «Protección de las señales transmitidas por redes informáticas».

- Propuesta del Gobierno de Brasil para el artículo i 2 que sugiere no incluir ninguna disposición de tal índole.

Como podemos observar, las cuantiosas reglas que contiene el documento de trabajo del tratado corresponde no sólo a un conjunto significativo de disposiciones, sino que además a un entramado de posturas diversas que hacen de su examen una tarea susceptible de confusión a simple vista. Asimismo, las muchas variantes que el texto contiene sólo nos confirman que aún subsisten ideas contrapuestas en temas de fondo, como las definiciones en el artículo 5, y las limitaciones y excepciones del artículo ro.

30. En dicha propuesta para la variante A del artículo 5 se presentan definiciones para las letras a), d) y j) de dicha disposición. 
Las diversas posiciones responden a los intereses de los múltiples Estados miembros que componen la OMPI, y que tienen una realidad nacional dispar en lo que a televisión, organismos de radiodifusión, mercado y regulación interna se refiere. La clásica diferenciación de los países entre desarrollados y en vías de desarrollo podría ayudarnos a entender este punto. Entre ambos tipos de países las diferencias respecto del mercado televisivo, la infraestructura de distribución de televisión y, consiguientemente, de sus organismos de radiodifusión es gigantesca. A todo ello tenemos que sumar que los organismos de radiodifusión más importantes a nivel global provienen de países desarrollados, que son titulares de grandes cantidades de contenidos y lo exportan fuera de sus fronteras, todo lo cual nos da algunas muestras de razonabilidad de la disparidad de variantes que vemos en el documento de trabajo (Screen Digest, 20Iob: 65).

A lo anterior tenemos que sumar el hecho de que en la discusión del tratado a lo largo de las sesiones del comité poco se ha dicho sobre el trasfondo del uso no autorizado de señales, aparte de los estudios coordinados por la misma OMPI y los propios estudios de los organismos de radiodifusión interesados en el tratado. El quid del asunto no es menor pues, según algunos autores, la piratería en la industria de medios responde, entre otras cosas, a los valores que se cobran en ciertos países para acceder legalmente a los contenidos, siendo éstos mayores en países menos desarrollados. Se postula también que la piratería se podría haber visto fomentada en el último tiempo por el bajo costo de las nuevas tecnologías y prácticas culturales cambiantes (Karaganis, 20I2: I I-I2).

\section{ARTÍCULOS 1 A 4}

Cada uno de los primeros cuatro artículos que componen el documento tienen sólo una variante, lo que demuestra cierto consenso de los países a la hora de regular tales puntos. Ahora bien, de su lectura podemos observar que son de carácter general y acordes a promover una correcta convivencia entre el tratado y:

a) el ordenamiento jurídico internacional ya existente: ${ }^{3^{1}}$ con el artí-

3I. El numeral tercero del artículo I también aporta a dicha convivencia: «El presente Tratado no tendrá conexión alguna con otros tratados ni perjudicará ningún derecho u obligación en virtud de los mismos». 
culo I ( «Relación con otros convenios y tratados»), que en su número primero señala: «Ninguna disposición del presente Tratado irá en detrimento de las obligaciones que las Partes Contratantes tengan entre sí en virtud de tratados multilaterales, regionales o bilaterales relativos al derecho de autor y los derechos conexos»;

b) la autonomía regulatoria de los Estados miembros: tanto por su artículo 2 ( «Principios generales» ${ }^{32}$ ), que asegura la independencia de los países a promover el acceso al conocimiento y la información, como por sus artículos 3 y 4 («Protección y promoción de la diversidad cultural» y «Defensa de la competencia»), que aseguran la independencia de los Estados a promover y proteger la diversidad cultural en sus respectivos países, y establecen que ninguna disposición del tratado va a prohibir que los Estados partes especifiquen en su normativa interna las prácticas concernientes a la concesión de licencias que puedan constituir abuso de derechos de propiedad intelectual;

c) los derechos que se tiene sobre el contenido emitido por los organismos de radiodifusión a través de su señal: establecido en el numeral segundo del artículo I que dispone expresamente: «La protección concedida en virtud del presente Tratado dejará intacta y no afectará en modo alguno la protección del derecho de autor y los derechos conexos sobre la materia transportada por las señales emitidas. En consecuencia, ninguna disposición del presente Tratado podrá interpretarse en el sentido de menoscabar esa protección».33

Una disposición parecida dispuesta en el mismo sentido, pero en términos mucho más amplios, la podemos encontrar en el artículo I de la Convención de Roma $^{34}$ que establece la no afección por la convención

32. Dicho artículo 2 del documento sobre Principios Generales expresa: «Ninguna disposición del presente Tratado limitará la libertad de una Parte Contratante de promover el acceso a los conocimientos, a la información y los objetivos nacionales en la esfera educativa y científica, combatir prácticas anticompetitivas o tomar toda iniciativa que se estime necesaria para promover el interés público en sectores de importancia fundamental para el desarrollo socioeconómico, científico y tecnológico».

33. Respecto de dicho numeral Japón expresa su propia versión: «La protección concedida en virtud del presente Tratado dejará intacta y no afectará en modo alguno la protección del derecho de autor y los derechos conexos respecto de material de programas incorporado en emisiones».

34. Dicho artículo I señala: «La protección prevista en la presente Convención dejará 
bajo ninguna alternativa de los derechos de autor. Empero, en el documento de trabajo observamos dos importantes diferencias. En primer lugar, la limitación de no afectación se extiende tanto a los derechos de autor como a los derechos conexos. En segundo término, el artículo I del documento especifica la funcionalidad de la norma, haciéndola aplicable únicamente a los derechos que existen sobre el contenido transportado por la señal del organismo de radiodifusión. Tales diferencias son apropiadas teniendo en cuenta los objetivos que se buscan con el tratado y todas las críticas que este mismo ha suscitado en parte de la sociedad civil, quienes lo han considerado como una barrera para la utilización del contenido radiodifundido. ${ }^{35}$

Con todo, creemos que en ese mismo numeral segundo se podría haber adicionado un inciso que impusiera una limitación para que no sea posible la afectación del contenido transportado en la señal y que se encuentre en el dominio público. O sea, haber ampliado la protección y no dejarla únicamente respecto del contenido que ya tiene titulares de derechos.

Finalmente, nos deja tranquilos la disposición del artículo 2 sobre «Principios generales» que apunta en ese sentido y que, como ya vimos en la letra anterior, resguarda la autonomía de los Estados para promover el acceso a los conocimientos y a la información. Empero, antes de poder contentarnos con dicho principio tenemos que comprobar si los derechos que se pretenden otorgar hacen realmente plausible dicha disposición en la práctica o sólo constituye una declaración de buenas intenciones con difícil aplicabilidad real (SCCR, 20I4: 2-3).

\section{ARTÍCULO 5, «DEFINICIONES»}

Este artículo cuenta con dos variantes principales (A y B), con once definiciones la primera y cuatro subvariantes, y seis definiciones la segunda y ninguna subvariante. Por subvariante entendemos aquellas variantes

\footnotetext{
intacta y no afectará en modo alguno a la protección del derecho de autor sobre las obras literarias y artísticas. Por lo tanto, ninguna de las disposiciones de la presente Convención podrá interpretarse en menoscabo de esa protección».

35. Véase Electronic Frontier Foundation, Broadcasting Treaty, disponible en <http:// bit.ly/ıOjSV $4 z>$.
} 
Cuadro 1. Artículo 5 del documento de trabajo «Definiciones».

\begin{tabular}{|c|c|}
\hline Variante A & Variante B \\
\hline letra a) Señal (con una subvariante) & letra a) Radiodifusión \\
\hline letra b) Emisión (con una subvariante) & letra b) Difusión por cable \\
\hline letra c) Organismo de radiodifusión & $\begin{array}{l}\text { letra c) Organismos de radiodifusión } \\
\text { y de difusión por cable }\end{array}$ \\
\hline letra d) Retransmisión (con una subvariante) & letra d) Retransmisión \\
\hline letra e) Fijación & letra e) Comunicación al público \\
\hline letra f) Comunicación al público & letra f) Fijación \\
\hline \multicolumn{2}{|l|}{ letra g) Señal anterior a la emisión } \\
\hline \multicolumn{2}{|l|}{$\begin{array}{l}\text { letra h) Información para la gestión de } \\
\text { derechos }\end{array}$} \\
\hline \multicolumn{2}{|l|}{ letra i) Transmisión } \\
\hline \multicolumn{2}{|l|}{$\begin{array}{l}\text { letra j) (otro) (con una subvariante: } \\
\text { Programa*) }\end{array}$} \\
\hline \multicolumn{2}{|l|}{ letra k) Difusión por cable } \\
\hline \multicolumn{2}{|c|}{$\begin{array}{l}\text { Fuente: Benussi Díaz (2014). } \\
\text { * En la letra j) sólo la subvariante contiene un concepto definido y que señala que programa corres- } \\
\text { ponde a: «un paquete específico constituido por una o más obras protegidas por derecho de autor o } \\
\text { derechos conexos en forma de material, en directo o grabado, compuesto por imágenes, sonidos o } \\
\text { ambos». Cabe destacar que dicha definición es más completa que la del Convenio Satélites de la OMPI } \\
\text { del año 1974, y que en su artículo } 1 \text { se refiere al concepto programa como: «todo conjunto de imágenes, } \\
\text { de sonidos, o de imágenes y sonidos, registrados o no, e incorporado a señales destinadas finalmente a } \\
\text { la distribución». }\end{array}$} \\
\hline
\end{tabular}

que existen dentro de una variante principal (A o B), y que en el artículo 5 sólo se aplican a un determinado concepto.

Según podemos observar en el cuadro I, ambas variantes se diferencian tanto en los conceptos que definen como en la cantidad de los mismos, concordando únicamente en: organismos de radiodifusión, retransmisión, difusión por cable, fijación y comunicación al público. Estos conceptos (excluyendo la difusión por cable) son —a nuestro juicio- los más importantes a la hora de determinar su definición, pues constituyen aquellos usos a los cuales las señales radiodifundidas pueden ser sometidas $^{36}$ y que, en la práctica, corresponden a aquellos hechos sobre los cua-

36. En este sentido véase los artículos 69 de la LPI, I4.3 del Acuerdo sobre los ADPIC y 13 de la Convención de Roma. 
les se les han otorgado derechos conexos a las entidades radiodifusoras alrededor del mundo, tanto en la regulación internacional (Convención de Roma y Acuerdo sobre los ADPIC) como en la legislación de nuestro país (LPI). En concreto, la definición de esos conceptos da cuenta del real y efectivo alcance de los derechos que se pretenden otorgar a los radiodifusores.

Sólo podemos puntualizar que hace falta el concepto de reproducción, que concierne a otro de los usos habituales a los que pueden estar sujetas las señales y que también corresponde a uno de los derechos conexos que les ha sido otorgado a los organismos radiodifusores. No obstante, dicho concepto ya ha sido definido tanto en la Convención de Roma como en nuestra propia LPI en su artículo 5 letra u), por lo que entendemos que su omisión puede no ser involuntaria por parte de los Estados. ${ }^{37}$

Dada la extensión del artículo, sólo examinaremos aquellos conceptos indicados previamente que coinciden en ambas variantes principales y donde parece haber mayor aquiescencia entre los Estados. Esta situación hace pronosticar que al finalizar las negociaciones tales conceptos tienen más probabilidades de permanecer en el texto definitivo del tratado que aquellos otros que sólo se encuentran en una sola variante (SCCR, 20I4: 4-5).

En primer lugar, la definición de organismo de radiodifusión tiene dos variantes ${ }^{38}$ (A y B), en ambos casos en la letra c) y con múltiples similitudes, a saber: a) en ambos casos constituyen personas jurídicas; b)

37. El artículo 3 de la Convención de Roma señala: «Reproducción, la realización de uno o más ejemplares de una fijación». Por su parte, el artículo 5 de la LPI indica en su letra u): «Reproducción: la fijación permanente o temporal de la obra en un medio que permita su comunicación o la obtención de copias de toda o parte de ella, por cualquier medio o procedimiento».

38. La variante A señala: «la persona jurídica que tome la iniciativa de la preparación, el montaje y la programación del contenido, habiendo obtenido a tal fin, de ser necesario, la autorización de los titulares de derechos, y asuma la responsabilidad jurídica y editorial de la comunicación al público de todo el material incluido en su señal emitida». Por su parte, la variante B expresa: «la persona jurídica que tome la iniciativa y asuma la responsabilidad de la transmisión al público de sonidos o de imágenes, o de imágenes y sonidos, o de las representaciones de éstos, y del montaje y la programación del contenido de la transmisión». 
en ambas las entidades se caracteriza por tomar la iniciativa en la transmisión de la señal; c) en ambas también las entidades son las encargadas del montaje y la programación del contenido que se transmite; y d) en las dos variantes los organismos son responsables de la transmisión de contenido que efectúen.

Sobre las diferencias que se presentan entre ambas variantes tenemos la siguiente: la letra c) de la variante B que se refiere a los organismos de radiodifusión hace también aplicable dicha definición a los «organismos de difusión por cable», cuestión que no acontece en la variante A, que sólo se limita a los organismos de radiodifusión. Sin embargo, advertimos que la definición de la variante A es tan amplia que podría incluir esta segunda clase de entidades, sumado a lo que dijimos en páginas anteriores en lo tocante a que los Estados miembros han especificado que con el tratado se busca conferir protección también a los organismos que transmiten a través de cable, alejándose de la concepción tradicional de organismo de radiodifusión. Es por ello que, al establecer una definición de organismo de radiodifusión como la vista en el documento de trabajo, se están incluyendo no sólo los organismos de radiodifusión que transmiten por aire, sino que también a los que lo hacen por medio de cable. ${ }^{39}$

Como se puede apreciar, ambos conceptos guardan bastante similitud diferenciándose en puntos mínimos.

Ahora revisaremos aquellos conceptos definidos en el artículo 5 y que constituyen los usos que tradicionalmente son base de los derechos que se han otorgado a las entidades radiodifusoras. Dichos usos son fijación, comunicación al público y retransmisión y que, como ya vimos, se repiten tanto en la variante A como en la variante $\mathrm{B}$.

Sobre el concepto fijación tenemos que señalar que éste se encuentra en la letra e) de la variante $\mathrm{A}$, y en la letra $\mathrm{f}$ ) de la variante $\mathrm{B} .4^{\circ} \mathrm{A}$ diferencia de lo que acontece con los organismos de radiodifusión, las definiciones del concepto fijación son exactamente similares entre las dos varian-

39. Es importante señalar que ambas definiciones difieren enormemente de lo que nuestra LPI ha entendido por organismo de radiodifusión y que para el tratado de la OMPI que estamos analizando no aplica.

40. En la variante A y B se define fijación como: «la incorporación de sonidos o imágenes, o de sonidos e imágenes, o de las representaciones de éstos, a partir de la cual puedan ser percibidos, reproducidos o comunicados mediante un dispositivo». 
tes. De ese modo podemos evidenciar sus características de la siguiente manera: a) una fijación a la luz del documento de trabajo comprende una incorporación de elementos; b) los elementos que deben incorporarse para estar dentro del ámbito de una fijación pueden ser los mismos. Estos elementos se distinguen entre sí como sonidos o imágenes, sonidos e imágenes y, por último, representaciones de sonidos o imágenes; c) finalmente, se requiere que dichos elementos incorporados deben tener la aptitud de ser percibidos, reproducidos o comunicados mediante un dispositivo.

Comparando esta definición con otras podemos decir que la OMPI ya se ha pronunciado sobre el concepto de fijación en un tiempo reciente, indicando que es aquella captura de una obra objeto de derechos conexos en alguna forma material (incluyendo memoria electrónica), de manera que a partir de ella pueda percibirse, reproducirse o comunicarse al público. Como vemos, dicha definición establece que para estar en presencia de una fijación se requieren de los mismos elementos que enumeramos en el párrafo anterior, por lo que no existen innovaciones en esta materia dentro del tratado (Ficsor, 2003: 294). $4^{\mathrm{I}}$

En lo que atañe al concepto de comunicación al público tenemos que considerar que éste se encuentra definido en la letra f) de la variante A, y en la letra e) de la variante B. ${ }^{42}$ Ambas definiciones difieren entre sí en su redacción pero guardan gran similitud en su objeto: a) en ambos casos se hace presente que el hecho primordial constituye que el público tenga acceso a la emisión del organismo radiodifusor; b) en ambos casos el evento que genera el acceso al público corresponde a una transmisión por aire, por cable o una retransmisión;43 c) por último, en ambas definiciones dicha transmisión o retransmisión puede ser hecha a través de cualquier plataforma, incluyendo —en consecuencia- las redes informáticas.

Es importante puntualizar que la comunicación al público es diferente

4I. En el mismo sentido lo establece la letra x) del artículo 5 de la LPI.

42. La letra f) de la variante A señala que la comunicación al público es «toda transmisión o retransmisión al público de una señal emitida, o una fijación de la misma, por cualquier medio o plataforma». La letra e) de la variante B expresa: «hacer que las transmisiones mencionadas en los apartados a), b) o d) del presente artículo sean audibles o visibles, o audibles y visibles, en lugares a los que tenga acceso el público».

43. Dicha conclusión se alcanza al revisar sistemáticamente todas las definiciones del artículo separadas por su respectiva variación. 
a la comunicación pública, en cuanto en el primer caso los destinatarios de las obras transmitidas y objeto de derechos conexos se encuentran en lugares diferentes. En definitiva, lo que distingue a ambos conceptos reside en si el acto supone o no la transmisión de la obra hacia un lugar diferente del origen de la emisión (Ficsor, 2003: 28I).

Corresponde referirnos por último al concepto de retransmisión ${ }^{44}$ que se encuentra en la letra d) de la variante A (con una subvariante denominada «retransmisión inalámbrica simultanea»), y en la letra d) de la variante B. 45

De su revisión se puede apreciar que ambas definiciones de retransmisión cubren sustancialmente lo mismo: a) En ambas se contempla que la actividad pueda ser realizada "por cualquier medio» para poder ser considerada retransmisión, incluyendo en consecuencia la transmisión efectuada por cable. En virtud de lo anterior estimamos que se está construyendo una definición de retransmisión diferente a la contemplada en nuestra LPI que, como sabemos, no incluye las transmisiones efectuadas por cable al contar con una definición de organismo de radiodifusión en sentido tradicional. b) Asimismo, se establece claramente que la retransmisión —en ambos casos- es únicamente procedente cuando la ejecuta cualquier persona que no sea el organismo que efectúa la transmisión originaria para su recepción por el público. c) Por último, es importante hacer la precisión acerca de la diferencia en las variantes, ya que es evi-

44. Para mayores antecedentes sobre las retransmisiones de señales de organismos de radiodifusión efectuadas por los cableoperadores en Chile, véase Benussi Díaz (20I4).

45. La letra d) de la variante A señala que retransmisión es: «la transmisión por cualquier medio, hecha por cualquier persona que no sea el organismo de radiodifusión originario, para su recepción por el público, de forma simultánea o diferida». En cuanto a su subvariante, señala que retransmisión inalámbrica simultánea es: «la transmisión simultánea de una emisión o una difusión por cable para su recepción por el público, hecha por cualquier persona que no sea el organismo de radiodifusión originario; se entenderá también por retransmisión inalámbrica simultánea, la transmisión simultánea de una retransmisión inalámbrica simultánea». Por último, la letra d) de la variante B indica sobre la retransmisión que ésta corresponde a «la transmisión simultánea al público por cualquier medio de una transmisión de las mencionadas en los apartados a) o b) del presente artículo, realizada por cualquier persona que no sea el organismo de radiodifusión o el organismo de difusión por cable originarios; se entenderá también por retransmisión, la transmisión simultánea de una retransmisión». 
dente la mayor amplitud que confiere la variante A en comparación a la $\mathrm{B}$ y que no se restringe a determinadas emisiones. En este sentido hay que agregar que los apartados a) y b) de la variante B, que contemplan los conceptos de radiodifusión y difusión por cable respectivamente, contienen disposiciones que excluyen a la transmisión por redes informáticas, cuestión que respecto de las definiciones de la variante A, no ocurre. Finalmente, hay que manifestar el hecho de que la retransmisión debe ser de carácter simultánea, o sea, en el mismo tiempo que se produce la transmisión por el organismo de radiodifusión. Esta cuestión es relevante pues configura la creación de un derecho referente a la transmisión posterior de fijaciones y que veremos más adelante.

Concluyendo, podemos observar cierta uniformidad entre las definiciones de los conceptos que calificamos como importantes y que se repiten en ambas variantes, lo que muestra que los Estados miembros han conciliado posiciones en esta parte del tratado y que las discrepancias se reducen a los otros conceptos del mismo.

\section{ARTÍCULO 6, «ÁMBITO DE APLICACIÓN»}

El ámbito de aplicación del tratado que se encuentra en el artículo 6 tiene dos variantes (A y B) con cuatro párrafos cada una..$^{46} \mathrm{Si}$ bien son dos variantes distintas, al menos en lo sustantivo presentan similitudes, a saber: a) En ambas variantes del artículo 6 se observa la intención de los Estados miembros de delimitar el ámbito de aplicación del tratado exclusivamente a las señales de los organismos de radiodifusión. b) En ambas variantes se especifica que el ámbito de aplicación excluye las obras o contenido incluido dentro de las señales de los organismos. Todo lo cual va en concordancia al mandato efectuado por la Asamblea General y que, según nuestro criterio, es fundamental para un funcionamiento

46. El párrafo I de la variante A señala: «La protección concedida en virtud del presente Tratado abarca únicamente las señales emitidas utilizadas para la transmisión por un organismo de radiodifusión, y no se extiende a las obras, ni a otra materia protegida, transportadas por dichas señales». A su vez, el párrafo I de la variante B dice: «La protección concedida en virtud del presente Tratado abarca únicamente las señales utilizadas para las transmisiones por los beneficiarios de la protección que confiere el presente Tratado, y no se extiende a las obras, ni a otra materia protegida, transportadas por dichas señales». 
adecuado del tratado debido a que las industrias protegidas utilizan y difunden obras intelectuales ya protegidas por derechos de autor. c) En ambas variantes además se excluye de protección a las retransmisiones.

En lo concerniente a las diferencias que se presentan entre las variantes de este artículo podemos señalar que son mínimas y no parecen ejercer un cambio de fondo en el núcleo de ambas disposiciones ${ }^{47}$ (SCCR, 20I4: 5-6).

\section{ARTÍCULO 7, «BENEFICIARIOS DE LA PROTECCIÓN» Y ARTÍCULO 8, "TRATO NACIONAL»}

Dichos artículos son breves y no presentan complejidad en su redacción actual en el documento de trabajo. Es importante destacar que, respecto de los beneficiarios de la protección, los Estados han concordado conferir la protección prevista en el tratado a aquellos organismos de radiodifusión que sean nacionales de otras partes contratantes. Acerca del artículo 8 sobre trato nacional, encontramos dos variantes A y B. La primera que tiene un párrafo único con una subvariante, y la segunda que presenta un párrafo segundo adicional. Si bien puede parecer confuso, los párrafos únicos presentan similares términos en cuanto a que cada parte contratante concederá a los organismos de radiodifusión nacional de otros Estados partes un trato no menos favorable que el que otorgue a sus propias entidades en virtud de la aplicación de los derechos del tratado. En consecuencia, existe uniformidad de criterio entre los Estados miembros para regular la obligación de trato nacional independiente de las variantes existentes actualmente (SCCR, 20I4: 6-8).

\section{ARTÍCULO 9, «PROTECCIÓN DE LOS ORGANISMOS DE RADIODIFUSIÓN»}

En este artículo encontramos dos variantes (A y B) que difieren en cuanto a la extensión de derechos exclusivos otorgados a los organismos de radiodifusión. En la variante A se contempla el derecho exclusivo del organismo a autorizar la retransmisión por cualquier medio, el derecho

47. Para apreciar dichas diferencias dirigirse al documento de trabajo y revisar los párrafos 3 y 4 de la variante A del artículo 6 y los párrafos 2 y 3 de la variante B del artículo 6 
Cuadro 2. Artículo 9, variante B, Protección de los organismos de radiodifusión.

\begin{tabular}{|l|}
\hline Derechos exclusivos a autorizar: \\
\hline i) Fijación de sus emisiones \\
\hline ii) Reproducción de la fijación de sus emisiones \\
\hline iii) Retransmisión de sus emisiones por cualquier medio \\
\hline iv) Comunicación al público de sus emisiones \\
\hline v) Puesta a disposición del público de las fijaciones de sus emisiones \\
\hline vi) Transmisión por cualquier medio de sus emisiones \\
\hline
\end{tabular}

exclusivo a autorizar la interpretación o ejecución de sus señales emitidas en lugares a los que tenga acceso el público, y el derecho exclusivo a autorizar la utilización de una señal anterior a la emisión que les estaba destinada.

Por su parte, como vemos en el cuadro 2, en la variante B se contiene un conjunto más amplio de derechos exclusivos y que conforman una batería de recursos que para los detractores del tratado van mucho más allá de ser presupuestos mínimos de protección para combatir el uso no autorizado de señales. Dicha variante B expresa que se otorga a los organismos de radiodifusión los derechos exclusivos de: autorizar la fijación de sus emisiones, la reproducción directa o indirecta de la fijación de sus emisiones, la retransmisión de sus emisiones por cualquier medio, la comunicación al público de sus emisiones, la puesta a disposición del público del original y copias de las fijaciones de sus emisiones de tal forma que puedan acceder a estas obras desde el lugar y en el momento que cada uno de ellos elija, la transmisión por cualquier medio de sus emisiones, y la puesta a disposición del público del original y de las copias de las fijaciones de sus emisiones mediante venta u otra transferencia de propiedad (SCCR, 20I4: 8).

Como podemos ver, ambas variantes conceden derechos de carácter exclusivo a diferencia de lo que acontece en la regulación de la Convención de Roma, que sólo otorga derechos a autorizar o prohibir determinados actos. No obstante, la doctrina ha declarado que dicha diferencia no es relevante a la hora de discutir su incidencia en los efectos de los derechos, señalando que en ambas denominaciones se puede generar una afectación de igual intensidad, no perjudicando a mayor nivel la libertad 
de expresión o el acceso de información por el hecho de ser los derechos del nuevo tratado, exclusivos (Dreier, 2006: 7).

Comparando el conjunto de derechos de la variante B es posible distinguir que ellos incluyen algunos que ya han sido regulados en la Convención de Roma y el Acuerdo sobre los ADPIC, como otros que no, y que serían nuevos en el ámbito internacional. Aquellos derechos que se repiten son: a) derecho de fijación; b) derecho de reproducción; c) derecho de comunicación al público; ${ }^{48}$ y d) derecho de retransmisión en el sentido tradicional. ${ }^{49}$ Así las cosas, observamos que la principal relevancia de éstos no radica en sí mismos, sino en su concesión a nuevos beneficiarios no contemplados en los anteriores instrumentos, como son aquellas entidades que transmiten vía cable.

En lo tocante a los nuevos derechos (no contemplados en la Convención de Roma ni en el Acuerdo sobre los ADPIC) que concede el documento de trabajo en su variante B del artículo 9 encontramos: a) derecho de retransmisión en un sentido amplio, inclusivo de la alámbrica y la por medio de redes informáticas; b) derecho de puesta a disposición del público de las fijaciones de sus emisiones de tal forma que los miembros del público puedan acceder a estas obras desde el lugar y en el momento que cada uno de ellos elija; c) derecho de transmisión por cualquier medio de sus emisiones, una vez fijadas, para su recepción por el público; y d) derecho de puesta a disposición del público de las fijaciones de sus emisiones, mediante venta u otra transferencia de propiedad. Junto a estos nuevos derechos que se otorgan a los organismos de radiodifusión tenemos que considerar lo que señala el párrafo 4 de la variante $B$, que ordena a los Estados miembros a conferir una protección jurídica adecuada y eficaz en relación con sus señales anteriores a la emisión. En consecuencia, estimamos la creación de un quinto derecho diferido: e) derecho de protección de las señales anteriores a la radiodifusión.

Este último derecho de protección de las señales anteriores a la redifusión tiene por objeto proteger aquellos casos en que la utilización de ellas por los organismos de radiodifusión acontece para transportar el

48. El derecho de comunicación al público en la Convención de Roma se limita a aquéllas realizadas en lugares accesibles al público mediante el pago de un derecho de entrada. Véase artículo 3 letra d) de la Convención de Roma.

49. Lo que también es retransmisión de carácter inalámbrica. 
contenido de una obra desde un estudio hasta el lugar donde está situado físicamente aquella entidad que será la transmisora final de la obra (Dreier, 2006: 8-9).

Sobre los derechos de puesta a disposición, podemos señalar que si bien éstos son una novedad en su otorgamiento a los radiodifusores, no lo son en el contexto internacional de la OMPI. El derecho de puesta a disposición al público fue otorgado anteriormente en los tratados WCT y WPPT en sus artículos 8 y ı respectivamente, por lo que en definitiva su inclusión no parece extraña (Dreier, 2006: 9).

Sobre el derecho de retransmisión señalado en el último párrafo, cabe destacar que en este caso se incluye la retransmisión inalámbrica simultánea, la retransmisión alámbrica (como la que desarrollan habitualmente los operadores de cable o también conocidos en Chile como permisionarios de televisión) y la retransmisión por redes informáticas (como las que se efectúan por la red de internet). ${ }^{\circ}$ Por lo demás, comparando esta disposición de la retransmisión con la de otros instrumentos internacionales vigentes, como la Convención de Roma y el Acuerdo sobre los ADPIC, se puede observar su extensión al evidenciar que en aquéllos la protección se concibe únicamente para aquellas retransmisiones efectuadas inalámbricamente o a través del espectro radioeléctrico, pues se configuraba al organismo de radiodifusión en su sentido tradicional. ${ }^{5}$ También hay que tener presente que, como vimos en el artículo 5 , la definición de retransmisión que contempla el apartado de la variante $\mathrm{B}$ considera a este hecho únicamente de forma simultánea, o sea, la que ocurre en el mismo tiempo que la señal es radiodifundida (Sehgal y Mathur, 20II: 406).

El derecho de transmisión de emisiones una vez fijadas responde a lo expuesto al final del párrafo anterior, y se condice con lo que mayoritariamente se entiende por retransmisión, que no cubre retransmisiones no simultáneas. Por ende, existiría una desprotección de aquellas señales ya

50. Con todo, cabe destacar que en el párrafo 2 de la variante B del artículo 9 se hace una precisión respecto de los derechos exclusivos de reproducción y retransmisión, señalando que corresponderá a la legislación nacional del Estado contratante determinar las condiciones del ejercicio del mismo, a condición de que dicha protección sea adecuada y eficaz.

5I. Véase la letra g) del artículo 3 de la Convención de Roma que define retransmisión. 
fijadas que se transmitan posteriormente, y a eso apunta la creación de este nuevo derecho de transmisión de emisiones ya fijadas. Su extensión, estimamos, se circunscribe a lo que en el ámbito de las definiciones se acuerde acerca del término transmisión.

Como vemos, la cantidad de derechos que el artículo 9 variante B otorga son bastantes. Algunos autores ya han postulado que de ser efectiva la creación del tratado, los beneficiarios de la protección alcanzarían un control casi completo sobre sus emisiones. Asimismo, se contemplan muchos derechos que ya son parte de aquéllos con que se ha protegido a titulares de derechos de autor, pero ahora se otorgan a una entidad que no es creadora, constituyendo dentro del sistema de propiedad intelectual una capa adicional de protección respecto de la cual el usuario forzosamente deberá vincularse. También se ha señalado que, al estar íntimamente ligado el contenido con la señal transmitida, en algunos eventos los derechos sobre esta última podrían verse posteriormente expresados, en la realidad, como derechos sobre las obras, sobre todo en aquel derecho exclusivo de reproducción de las fijaciones (Balganesh, 2007: I3 I6-I328).

\section{ARTÍCULO 10, «LIMITACIONES Y EXCEPCIONES»}

El artículo ro del documento de trabajo cuenta con tres variantes (A, B y C), A y B con dos párrafos cada una, y C con tres (SCCR, 20I4: 9).

En la variante $A$, el primer párrafo contiene cuatro excepciones a la protección para los siguientes casos: a) utilización de carácter privado; b) utilización breve de fragmentos con motivo de informaciones sobre sucesos de actualidad; c) utilización con fines exclusivamente docentes y de investigación científica; y d) fijación efímera realizada por un organismo de radiodifusión por sus propios medios y para sus propias emisiones. En el párrafo segundo se establece la posibilidad de que cada Estado establezca como excepciones o limitaciones las mismas que se aplican para las obras protegidas por derechos de autor, «en la medida en que dichas excepciones se restrinjan a casos especiales que no atenten contra la explotación normal de la señal emitida ni causen un perjuicio injustificado a los intereses legítimos del organismo de radiodifusión».

Por su parte, el párrafo primero de la variante B no hace una lista de excepciones, sino que concede a los Estados la posibilidad de establecer 
las mismas excepciones que existen para las obras protegidas por derechos de autor en su derecho interno. En su párrafo segundo, y al igual que el párrafo segundo de la variante anterior, se señala que los Estados deben restringir las excepciones a ciertos casos especiales que no atenten contra la explotación normal de la emisión ni causen un perjuicio injustificado al organismo de radiodifusión.

Finalmente, la variante $\mathrm{C}$, al igual que las dos anteriores, configura la posibilidad de los Estados de conceder las mismas excepciones que en su derecho interno se establecen para la utilización de obras protegidas por derechos de autor siempre y cuando se restrinjan a casos especiales que no causen un perjuicio injustificado. La particularidad de esta variante radica en el párrafo segundo, que contiene una lista de excepciones y limitaciones que pueden ser establecidas por las Partes Contratantes en su regulación interna. Dichas excepciones incluyen aquellas que contiene la variante A y agrega además otras: a) utilización de obras específicamente para fomentar el acceso a las mismas por personas con problemas de vista u oído, de aprendizaje u otro tipo de discapacidad; b) utilización por bibliotecas, archivos, o instituciones docentes, con el fin de poner a disposición del público copias de obras protegidas por los derechos exclusivos de los organismos de radiodifusión, para fines de preservación, educación o investigación; c) toda utilización del tipo que sea y de la forma que sea de cualquier parte de una emisión cuando el programa, o parte del mismo, que sea el objeto de la transmisión no esté protegido por un derecho de autor o un derecho conexo.

La existencia de tres variantes sólo expresa la diversidad de opiniones que aún subsisten entre los Estados partes sobre este punto, y su examen detallado excede los límites del presente trabajo. A pesar de lo anterior, podemos señalar que las excepciones y limitaciones son parte fundamental para crear el equilibrio regulatorio que se necesita entre la protección que se quiere conceder a los radiodifusores y el interés público de la sociedad. Compartimos la idea de que una adecuada disposición de excepciones y limitaciones puede permitir que los Estados partes puedan garantizar el uso y flujo de información y el acceso al conocimiento, sobre todo para aquellos estratos sociales más bajos que no pueden pagar por ellos (Muñoz, 2007: 6-7).

Por lo demás, el hecho de que cada Estado pueda crear otras excepciones parece una adecuada salida para tan complejo asunto, pudiendo 
adecuarse específicamente a la realidad concreta del país. Sin embargo, estimamos que una disposición de esa naturaleza será realmente útil cuando: a) se defina bien la limitación que se propone: «en la medida de que dichas excepciones se restrinjan a casos especiales que no atenten contra la explotación normal de la señal emitida ni causen un perjuicio injustificado a los intereses legítimos del organismo de radiodifusión»; y b) se establezca un mínimo de excepciones y limitaciones fijo, no sujeto a posterior revisión por parte del Estado, con la finalidad de generar certidumbre regulatoria en los usuarios de obras radiodifundidas (Electronic Frontier Foundation, 2007: I-2).

\section{ARTÍCULO 11, «PLAZO DE PROTECCIÓN»}

El artículo i del documento de trabajo cuenta con dos variantes (A y B) que van desde conceder una protección de cincuenta años hasta no fijar plazo ninguno, sin que de su revisión se pueda desprender una clara postura del documento. Con todo, ha tomado bastante fuerza que la protección concedida a los organismos de radiodifusión sobre sus emisiones sea de cincuenta años, superando con creces los veinte años que establece la Convención de Roma y el Acuerdo sobre los ADPIC (SCCR, 2008: 7-8).

La propuesta de conceder un plazo de cincuenta años ha generado bastantes críticas desde la arista que defiende la libertad de expresión y acceso a la información. Sin embargo, cabe recordar que el plazo que gozan los productores de fonogramas es de cincuenta años según el artículo I7 del tratado WTTP. Por su parte, los organismos de radiodifusión han defendido dicho plazo en virtud de las inversiones que hacen para poder realizar su actividad (Dreier, 2006: I4).

\section{ARTÍCULOS 12 Y $13^{52}$}

Los artículos I 2 y I 3 presentan una serie de particularidades en el documento de trabajo que muestran nuevamente la disparidad de criterios aún existentes entre los Estados miembros. Su análisis es en conjunto, pues la existencia del artículo I 3 depende de cuál de las variantes del artículo $\mathrm{I} 2$ se conserve definitivamente en el tratado.

52. Véase Dreier, 2006: I I-I2. 
El artículo I 2 contiene dos variantes (A y B), y éstas cuentan con dos subvariantes cada una: AI, A2, BI y B2. Ambas subvariantes de la variante A se denominan «Protección de la codificación y la información para la gestión de los derechos», y ambas buscan establecer que los Estados partes deben conceder en su legislación interna protección jurídica contra los actos no autorizados de: a) decodificar una emisión codificada; y b) suprimir o alterar información electrónica referente a la aplicación de la protección de los organismos de radiodifusión. Estas subvariantes difieren entre sí pues la subvariante Ai además busca que se conceda protección jurídica contra el acto de «fabricar, importar, vender o cualquier otro acto que ponga a disposición un dispositivo o sistema que descodifique una emisión codificada».

En lo que atañe a las dos subvariantes de la variante B, éstas se denominan «Obligaciones relativas a las medidas tecnológicas», las que en ambos casos buscan que los Estados contratantes concedan una protección jurídica y recursos legales contra la elusión de medidas tecnológicas de protección que empleen los organismos de radiodifusión para proteger sus derechos. Si alguna de estas dos subvariantes de B se mantiene, se conservara el actual artículo I3 que se denomina «Obligaciones relativas a la información para la gestión de derechos» y que contempla una sola variante. ${ }^{53}$

53. El artículo I 3 del documento de trabajo señala: «I) Las Partes Contratantes proporcionarán recursos jurídicos adecuados y efectivos contra cualquier persona que, con conocimiento de causa, realice cualquiera de los actos siguientes sabiendo o, respecto de los recursos civiles, teniendo motivos razonables para saber que induce, permite, facilita u oculta una infracción de cualquiera de los derechos previstos en el presente Tratado: i) suprimir o alterar sin autorización cualquier información electrónica sobre la gestión de derechos; ii) distribuir o importar fijaciones de emisiones para su distribución, realizar la retransmisión o comunicación de emisiones al público, o transmitir o poner a disposición del público emisiones fijadas, sin autorización, sabiendo que la información electrónica para la gestión de derechos ha sido suprimida o alterada sin autorización en la emisión o la señal anterior a la emisión. 2) En el presente artículo se entenderá por 'información para la gestión de derechos' la información que identifica al organismo de radiodifusión, a la emisión, al titular de cualquier derecho sobre la emisión, o la información sobre las cláusulas y condiciones de utilización de la emisión, y todo número o código que represente tal información, cuando cualquiera de estos elementos de información esté adjunto o asociado a I) la emisión o la señal anterior a la emisión, 2) la retransmisión, 3) la transmisión posterior a la fijación de la emisión, 4) la puesta a disposición de una emisión fijada, o 5) la copia de una emisión fijada». 
A simple vista se puede concluir que la diferencia de criterios sólo subyace en la intensidad de la medida, pero no en su aplicabilidad. Parece claro para los Estados miembros que debe existir una regulación en el tratado acerca de las medidas tecnológicas de protección, pero se evidencia que falta todavía afinar los detalles de una norma definitiva. También se puede concluir la intención de hacer que los Estados construyan sus propias acciones judiciales para que los organismos de radiodifusión puedan dirigirse efectivamente contra aquellos que busquen realizar alguna de las acciones descritas eludiendo la medida tecnológica (Balganesh, 2007: I316).

Por último, consideramos que una creación desprolija de esta norma conllevaría graves consecuencias que podrían incluso afectar a aquellos consumidores que legítimamente estén haciendo uso de una emisión radiodifundida.

ARTÍCULO 14, "DISPOSICIONES SOBRE LA OBSERVANCIA DE LOS DERECHOS», ARTÍCULO 15, «FORMALIDADES», Y ARTÍCULO 16, "APLICACIÓN EN EL TIEMPO»

El actual documento de trabajo del tratado concluye con los artículos I 4, I 5 y I 6 y en donde sólo existe una variante para cada uno de ellos. Dichas disposiciones son más bien generales y buscan la correcta aplicación del tratado.

Muestra de lo anterior es el artículo I4 que, en su párrafo primero, señala: "Las Partes Contratantes se comprometen a adoptar, de conformidad con sus sistemas jurídicos, las medidas necesarias para asegurar la aplicación del presente tratado». También vale la pena mencionar el párrafo primero del artículo I 6 que busca que los Estados concedan protección en virtud del tratado a toda emisión fijada o emisión fijada que exista en el momento de la entrada en vigor del tratado.

\section{CONSIDERACIONES SOBRE EL TRATADO Y CRÍTICAS PRINCIPALES}

Como sabemos, muchas críticas ha generado la eventual creación de este tratado de protección a los organismos de radiodifusión, por lo que estimamos oportuno concluir este trabajo revisando algunas de las más relevantes y reiteradas. Éstas provienen de múltiples fuentes, como el mundo académico, la sociedad civil, las asociaciones de artistas, intér- 
pretes y ejecutantes, compañías de tecnología y de medios de comunicación, grupos de interés público, países en vías de desarrollo, entre otros. Entre las críticas más importantes vale destacar las siguientes.

\section{PERJUDICA A LOS CONSUMIDORES, NO SOLUCIONA LA PIRATERÍA DE SEÑALES Y FORTALECE EL NEGOCIO DE LAS ENTIDADES RADIODIFUSORAS}

Se ha señalado que el tratado no proporciona ningún beneficio a la sociedad y a los consumidores de contenido. Asimismo, se ha indicado que al impulsar el poder de mercado de los organismos de radiodifusión, éstos pueden acrecentar su monopolio sobre el suministro de obras y aumentar su capacidad para determinar los precios, lo que puede resultar a la larga perjudicial para los consumidores (SCCR, 20I0: 8).

Este último tema ha sido bastante discutido llegando a señalarse que, a través del nuevo tratado, aumentarían los costos de transacción de las operaciones vinculadas a la utilización de contenidos cuando éstos se encuentren únicamente incorporados en una señal de un organismo de radiodifusión determinada, en el entendido de que aquel solicitante o usuario de los derechos tendrá que llevar a cabo dos negociaciones — quizás— independientes, una por la señal y otra por el contenido o programa de televisión (Balganesh y otros, 2004: 4).

También se ha discutido si efectivamente el otorgamiento de nuevos derechos exclusivos sería una real solución para el uso no autorizado de señales, o sólo implicaría una estrategia para que los organismos de radiodifusión alcancen antiguas ganancias y beneficios que fueron disminuidos por el desarrollo tecnológico. De esa manera, se ha mencionado que el avance de métodos alternativos de distribución de información propiciado por dichos avances ha mermado el monopolio de los organismos de radiodifusión como entidades proveedoras de información a la sociedad y, con ello, perjudicado sus utilidades y su audiencia. Finalmente, con la creación del tratado no se solucionaría el uso no autorizado de señales, ni se mejoraría la posición de los radiodifusores, perjudicando y distorsionando el actual panorama de derechos existentes (Bates y Wells, 2007: 35-36).

Otros autores han llegado a decir que, mediante el tratado propuesto, la OMPI en conjunto con las delegaciones estarían protegiendo el modelo de negocios de los organismos de radiodifusión, concluyendo 
que la forma adecuada de combatir los problemas que aquejan a estas entidades es la regulación nacional y no la que se propone a nivel internacional. En este sentido consideramos que no se debe imponer un único modelo a un conjunto de países, pues la solución propuesta puede no ser la adecuada para su realidad nacional. En ese sentido, somos partidarios de la incorporación de algunas cláusulas abiertas en donde el mismo Estado pueda posteriormente regular en base a su contexto interno. Esto toma mayor fuerza ahora que las consecuencias del tratado aún no son claras, y sobre todo con la importancia que implica hacerlo obligatorio a nivel mundial (Kretschmer, 2006: I-2).

\section{RESTRICCIONES A LA LIBERTAD DE EXPRESIÓN}

Relativo a las implicancias que este instrumento traería para la libertad de expresión, Akester ha señalado que la entrega de estos nuevos derechos a los organismos de radiodifusión — junto a lo dispuesto con las medidas tecnológicas de protección- podría restringir el flujo de información, sobre todo respecto de obras que quizás no estén necesariamente protegidas por derechos de autor.

En consecuencia, se podría generar una merma al derecho de libertad de expresión en el entendido de, por ejemplo, prevenir o dificultar a los ciudadanos el uso de obras que se encuentren en el dominio público una vez que éstas sean transmitidas por la entidad de radiodifusión beneficiaria del tratado y titular de la batería de derechos exclusivos que vimos en apartados anteriores (Akester, 2006: $3 \mathrm{I}-44$ ).

\section{DURACIÓN EXCESIVA DE PROTECCIÓN}

La duración de la protección que se quiere entregar también ha sido criticada, teniendo en cuenta que actualmente existe una variante del artículo i I (A), «Plazo de protección», que otorga cincuenta años de protección contados a partir del final del año en que se haya emitido la señal. Con esta situación se cuestiona si esa cantidad de tiempo es acorde con una política de recuperación de las inversiones desarrolladas por los organismos de radiodifusión o corresponde simplemente a un mecanismo para proteger cierto modelo de negocios. Podemos observar que una protección de cincuenta años es difícilmente justificable teniendo presen- 
te que tanto el Acuerdo sobre los ADPIC como la Convención de Roma otorgan protección por un plazo de sólo veinte años.

Por último, hay que tener siempre en cuenta que no estamos confiriendo protección a creadores de obras intelectuales, sino que a meros ayudantes en la difusión de aquéllas. Creemos que precisamente por la difusión de las nuevas tecnologías de la información —lideradas por la red global internet-, los medios de distribución de contenido se han ampliado de forma tal que la relevancia de los organismos de radiodifusión en el sentido tradicional y su modelo de negocios ha ido reduciéndose, hecho que debe tenerse en cuenta por los Estados miembros.

\section{EXCESIVOS DERECHOS}

Opiniones originadas desde la sociedad civil anglosajona ${ }^{54}$ se han expresado escépticas del presente tratado, principalmente acerca de si el otorgamiento de nuevos derechos a los organismos de radiodifusión vendría a introducir una nueva capa de protección sin la claridad necesaria para adaptarse correctamente al sistema de copyright, la política regulatoria de Estados Unidos ejercida por la Federal Communications Commission (FCC) y el régimen de retransmisión consentida. Estas mismas fuentes señalan además que este tratado, al ser inconsistente con las leyes estadounidenses de copyright, lesionaría los derechos de los titulares de los contenidos dándole primacía en el sistema de propiedad intelectual a los ayudantes en la difusión de las obras y no a los verdaderos creadores de éstas, generando probablemente una grave interferencia de derechos (Public Knowledge, 20I I: 2-4).

Del mismo modo, pero ahora en el contexto internacional y desde el punto de vista del consumidor, se ha señalado que la creación de derechos exclusivos para las entidades radiodifusoras sobre la transmisión de emisiones y reproducción de fijaciones conllevaría agregar una capa

54. En este contexto también se ha señalado que la industria radiodifusora tanto por aire como por cable funciona de buena manera aun cuando Estados Unidos no ha adherido a la Convención de Roma. Es por esto que se ha indicado que Estados Unidos no necesitaría la creación de un tratado para estimular el progreso de dichas industrias, con derechos que no son conocidos para ellos, sobre todo cuando no se tiene gran claridad respecto del impacto que podrían tener dichos nuevos derechos en la sociedad, los educadores, los actuales titulares de derechos de autor e internet (Lee, 2009: 4). 
extra a la protección ya otorgada por los derechos de autor. Dicha nueva capa generaría una restricción para los ciudadanos de acceder a obras que se encuentren en el dominio público pero que hayan sido transmitidas por una señal protegida de un organismo de radiodifusión. En consecuencia, tal ciudadano que ayer podía acceder legítimamente a esas obras por haber ingresado al dominio público, hoy tiene una barrera más en virtud de los derechos de los radiodifusores, situación que afectaría el acceso a la información de toda la sociedad sin distinción (Electronic Frontier Foundation, 2007: I-2).

\section{PERJUICIO A PAÍSES EN VÍAS DE DESARROLLO 55}

Referente a este punto, diversos autores han indicado que la creación del tratado de protección a los organismos de radiodifusión concebiría un menoscabo para los países en vías de desarrollo, pues al crear derechos exclusivos sobre casi toda utilización posible de una señal radiodifundida se estaría limitando su acceso a obras existentes en el dominio público y transmitidas mediante dichas señales. La afección se ve incrementada cuando se tiene presente que la mayor cantidad de obras intelectuales son creadas en países del primer mundo y que cuentan con las industrias radiodifusoras más importantes e influyentes a nivel internacional. En consecuencia, esta barrera vería mermada su posibilidad de acceder al conocimiento y, con ello, se estaría perjudicando a futuro su avance y desarrollo económico (Sehgal y Mathur, 20I I: 402-408).

Con todo, esta postura puede ponerse en tela de juicio al evidenciar que actualmente en los debates ante la OMPI uno de los grupos de Estados miembros más profundamente encaminados a la conclusión pronta del tratado es el de países africanos, que justamente está compuesto por países en vías de desarrollo. Según las propias declaraciones de sus de-

55. En relación con esto se ha indicado que el tratado para los países en desarrollo debería tener como eje fundamental potenciar el acceso a los conocimientos y el flujo de información. Todo lo cual a la larga promovería el progreso y la innovación, el desarrollo de industrias nacionales tanto de radiodifusión como de derechos de autor. Las medidas de nuevos derechos exclusivos para las entidades radiodifusoras, su plazo excesivamente prolongado de protección, como actualmente establecen las variantes vistas en el último documento de trabajo, no irían en esa dirección y, por lo tanto, no sería un instrumento útil para los países en vías de desarrollo (Muñoz y Chege, 2007: 62). 
legaciones, con el tratado se potenciaría su emergente industria radiodifusora y su industria creativa (Asamblea General OMPI, 201 5: 34-37).

Con estos dispares antecedentes sólo se puede concluir preliminarmente que la eventual concreción de un tratado de estas características puede conllevar tanto perjuicios como beneficios dependiendo del tópico específico en el cual nos encuadremos. En el caso de los países en vías de desarrollo, concordamos con la crítica expresada en el primer párrafo, pero teniendo en cuenta que eso es un perjuicio circunscrito al acceso al conocimiento y el flujo de información. Asimismo, si sólo pensamos en el desarrollo y potenciamiento de una emergente industria radiodifusora con expectativas de expansión hacia países colindantes, está claro que el tratado ayudaría a tal objeto, siendo aquí de un beneficio evidente.

\section{DETRIMENTO A NUEVAS TECNOLOGÍAS}

Algunos autores han contemplado que nuevas tecnologías con poco tiempo en el mercado se podrían ver perjudicadas con la creación de los nuevos derechos para los organismos de radiodifusión respecto de sus emisiones. Tales serían los DVR (Digital Video Recorders) que fijan o graban emisiones para su posterior reproducción, Slingbox que retransmiten contenido radiodifundido a través de internet y Video Bajo Demanda $(\mathrm{VoD})$, que fija contenido para su uso posterior según la elección del usuario. Todo lo cual nos parece probable, sobre todo para el servicio que Slingbox brinda y que lo podemos vincular con el numeral 3 de la variante B del artículo 9, que señala que los organismos de radiodifusión gozaran el derecho exclusivo a «iii) autorizar la retransmisión de sus emisiones por cualquier medio, incluida la retransmisión inalámbrica simultánea, la retransmisión alámbrica y la retransmisión por redes informáticas». En este sentido, la protección de los organismos de radiodifusión al alcanzar las redes informáticas (o de internet) conlleva la posibilidad de disponer del uso o no de su señal por Slingbox, cuestión que no se encuentra regulada en la Convención de Roma ni en el Acuerdo sobre los ADPIC (Bates y Wells, 2007: 6).

Igualmente, los derechos exclusivos otorgados a los organismos de radiodifusión respecto de la retransmisión de sus emisiones a través de redes informáticas ha generado bastante controversia en cuanto al posible impacto negativo que podría producir sobre internet, así como tam- 
bién probablemente suscitar un desequilibrio frente a nuevos competidores de la industria que elijan difundir exclusivamente por esa vía (Muñoz y Chege, 2007: 44-45).

\section{FALENCIAS EN CUANTO A PRIVACIDAD}

Sobre privacidad se ha contemplado que las regulaciones propuestas sobre medidas tecnológicas de protección incrementarían el riesgo de amenazar la privacidad de los usuarios de aquellos contenidos protegidos por los organismos de radiodifusión. Con ello se podrían crear diversas situaciones en donde las entidades tendrían acceso a información privada de los usuarios que utilicen sus señales legítimamente. Esto se podría ver agravado por la masividad con que internet está funcionando en casi todos los dispositivos del hogar, pudiendo generar peligros a la privacidad donde información reservada del consumidor llegue a la entidad radiodifusora, titulares de derechos de autor, fabricadores de dispositivos y otros (Dopplick, 2007: II).

\section{CONSIDERACIONES FINALES}

A partir de lo que hemos revisado en los párrafos anteriores es posible advertir que el tratado de protección a los organismos de radiodifusión impulsado por la OMPI y las delegaciones de los Estados miembros aún se encuentra en proceso de elaboración. Basta leer el articulado del último documento de trabajo disponible SCCR/27/2 REV (con sus múltiples variantes) para dar cuenta de que todavía existen diversos criterios en importantes materias entre los Estados miembros.

En cuanto a las razones que han sustentado la creación del tratado, creemos que es legítima la necesidad expuesta por las entidades radiodifusoras de buscar mejorar la protección de sus señales ante el uso no autorizado de éstas. Empero, consideramos que se debe tener precaución a la hora de conceder a estos organismos nuevos derechos exclusivos con largos plazos de protección que podrían desencadenar un desequilibrio frente al interés social y de los países en vías desarrollo de acceder a la información. Todos los países tienen realidades y objetivos diferentes, y por ello se debe buscar un instrumento equilibrado que se ajuste a lo que todos necesitan. 
Hoy en día no hay pruebas concretas que muestren que a través del otorgamiento de nuevos derechos se pueda combatir de forma efectiva y adecuada el uso no autorizado de señales. Sumado a ello, el profesor Robert Picard en un estudio hecho para la OMPI ha declarado que «no hay manera de predecir eficazmente cuáles serán los efectos del tratado, a escala mundial, respecto de los usos no autorizados o qué consecuencias económicas traerá aparejadas su puesta en marcha, debido a la carencia de la información necesaria». Dicha realidad sólo evidencia que aún hay un importante camino por recorrer para alcanzar la regulación correcta sobre un tema tan delicado. Por último, esto sólo genera sobre los Estados miembros un peso de responsabilidad mayor respecto de las medidas que posteriormente vayan a adoptar y que, como dijimos, debe dirigirse al buen equilibrio de intereses entre todas las partes involucradas (Picard, 2010: 90).

\section{REFERENCIAS}

Akester, Patricia (2006). "The draft WIPO Broadcasting Treaty and its impact on freedom of expression». Copyright Bulletin (Unesco), abril-junio. Disponible en <http://bit.ly/IfjhpiS>.

Antequera Parilli, Ricardo (1998). Derecho de autor. Caracas: Editorial Venezolana.

Asamblea General OMPI (20I4). Informe sobre la labor del comité permanente de derecho de autor y derechos conexos. Ginebra. Disponible en <http://bit.ly/IIgnrfF>.

-. (2015). Informe aprobado por la Asamblea General del cuadragésimo sexto periodo de sesiones $\left(25{ }^{\circ}\right.$ extraordinario). Ginebra. Disponible en <http://bit.ly/IDs9Bky>.

Balganesh, Shyamkrishna y otros (2004). Report on the draft WIPO Broadcasting Treaty. Disponible para descarga directa en formato Word en <http://bit.ly/1CNkin7>.

Balganesh, Shyamkrishna (2007). "The social costs of property rights in bradcast (and cable) signals». Berkeley Technology Law Journal, 22: I303-I387. Disponible en <http://bit.ly/IJeicxC>.

Bates, Benjamin J. y D. Scott Wells (2007). "Are broadcaster rights in the public interest? A social economic analysis of the WIPO's draft 
broadcast treaty». College of Communication and Information (University of Tennessee). Disponible en <http://bit.ly/IJuuRs9>.

Benussi Díaz, Carlo (20I4). Organismos de radiodifusión y la retransmisión de sus señales en la legislación de propiedad intelectual. Memoria para optar al grado de Licenciado en Ciencias Jurídicas y Sociales, Universidad de Chile. Disponible en <http://bit.ly/1Ij4Uzf>.

SCCR, Comité Permanente de Derecho de Autor y Derechos Conexos (I998). Legislación vigente a nivel internacional, regional y nacional en materia de protección de los derechos de los organismos de radiodifusión. Disponible en <http://bit.ly/ıJepb9Z>.

-. (2002). La protección de los organismos de radiodifusión: Términos y conceptos. Disponible en <http://bit.ly/1HLvjnD>.

-. (2008). The WIPO Treaty on the Protection of Broadcasting Organisations. Disponible en <http://bit.ly/IeecgI6>.

-. (20I0). Documento analítico relativo al Estudio sobre la dimensión socioeconómica del uso no autorizado de señales, partes I, II y III. Disponible en <http://bit.ly/ICTjugm>.

-. (20I4). Documento de trabajo relativo a un tratado sobre la protección de los organismos de radiodifusión. Disponible en $<\mathrm{http}$ ://bit. ly/rTNSPpD>.

Cooper C., Rodrigo (20II). Derecho de propiedad intelectual de los canales de televisión de autorizar o no la difusión de sus señales o programas por un organismo distinto, en particular por empresas distribuidoras de señales de televisión por cable. Informe en Derecho. Santiago.

Croella, Carole (20II). "Seminar on intellectual property and sports». Jamaica. Disponible en $<$ http://bit.ly/IIhPcpL $>$.

Dopplick, Renee (2007). «Proposed WIPO treaty on the protection of the rights of broadcasting organizations: Privacy implications of fighting digital pirates». Disponible en <http://papers.ssrn.com/sol3/ papers.cfm?abstract_id $=1222724>$.

DreIER, Thomas (2006). "Reflections on the draft WIPO broadcasting treaty and its impact on freedom of expression».e-Copyright Bulletin (Unesco), julio-septiembre. Disponible en <http://bit.ly/IHGyL2S>.

Electronic Frontier Foundation (2007). Electronic Frontier Foundation position paper on the proposed WIPO broadcasting treaty. San Francisco, Estados Unidos. Disponible en <http://bit.ly/IgM2yys>. 
FICSOR, Mihály (2003). Guía de los tratados de derecho de autor y derechos conexos administrados por la OMPI. Ginebra: OMPI. Disponible en <http://bit.ly/IIbnGEa>.

Grunewaldt Cabrera, Andrés (20I3). «Delitos contra los derechos de autor en Chile». Revista Chilena de Derecho y Tecnología, 2 (2): 95I63. Disponible en <http://bit.ly/IKiMsXI $>$.

Karaganis, Joe (editor) (20I2). Piratería de medios en las economías emergentes. Trad. de Clio Bugel y Guillermo Sabanes. Social Science Research Council. Disponible en <http://bit.ly/ISzuloS>.

Kretschmer, Martin (2006). «A wider net? The proposed WIPO broadcasting treaty: What do you do with rights you don't need?». Copyright World.

LEE, Margaret Mikyoung (2009). World Intellectual Property Organization (WIPO) Treaty on the Protection of Broadcasting Organizations. Washington DC: Congressional Research Service.

Public KNOWLedge (20I I). "How the WIPO broadcast treaty conflicts with American media policy». Disponible en <http://bit.ly/IJelu40>.

SCREen Digest (20IOa). Estudio sobre la dimensión socioeconómica del uso no autorizado de señales (II): Acceso no autorizado a contenidos de radiodifusión. Causas y efectos: Panorama mundial. Londres: OMPI. Disponible en <http://bit.ly/ICTfEUl>.

-. (20I0b). Estudio sobre la dimensión socioeconómica de la utilización no autorizada de señales: parte I: Actuales tendencias del mercado y la tecnología en el sector de la radiodifusión. Londres: OMPI. Disponible en <http://bit.ly/ITTsdne>.

Sehgal, Divyanshu y Siddharth Mathur (20II). «Rights and duties of broadcasting organizations: Analysis of WIPO treaty on the protection of broadcasting organizations». Journal of Intellectual Property Rights, I6. Disponible en <http://bit.ly/rLqjOWV>.

McGann, James G. (coord.) (20I5). 20I4 Global Go to Think Tank Index Report. Pennsylvania: University of Pennsylvania. Disponible en <http://bit.ly/IOurZzW>.

MuÑoz, Viviana (2007). «The proposed WIPO treaty on the protection of broadcasting and cablecasting organizations». South Centre. Policy Brief, 8. Disponible en <http://bit.ly/1HGBvgO>.

MuÑoz, Viviana y Andrew CHege (2007). «A development analysis of 
the proposed WIPO treaty on the protection of broadcasting \& cablecasting». South Centre: Research Paper, 9.

Muñoz Tellez, Viviana y Sisule F. Musungu (2010). «A2K at WIPO: The development agenda and the debate on the proposed broadcasting treaty». En Gaëlle Krikorian y Amy Kapczynski (editores), Access to knowledge in the age of intellectual property. Nueva York: Zone Books.

PICARD, Robert G. (20I0). Estudio sobre la dimensión socioeconómica del uso no autorizado de señales (Parte III): Estudio sobre los efectos sociales y económicos de la Propuesta de Tratado para la Protección de los Organismos de Radiodifusión. Disponible en <http://bit. ly/IGyTDFf $>$.

Woods, Michele (2014). The normative copyright and related rights agenda at WIPO. Disponible en <http://bit.ly/ISzxlKG>.

\section{SOBRE EL AUTOR}

Carlo Benussi Díaz es abogado. Licenciado en Ciencias Jurídicas y Sociales de la Facultad de Derecho de la Universidad de Chile. Su correo electrónico es <c.benussi@gmail.com>. Su dirección postal es Miguel Claro I457, Providencia, Santiago.

Este trabajo fue recibido el I 2 de marzo de 20 I 5 y aprobado el I 5 de junio de 2015 . 
